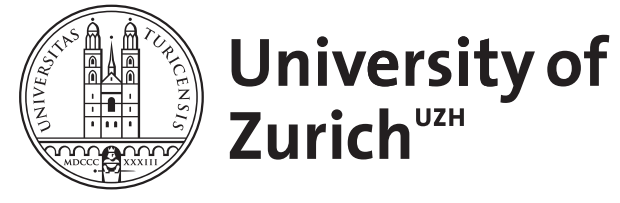

\title{
Modelling the emergence and stability of a vertically transmitted cultural trait in bottlenose dolphins
}

\author{
Kopps, A M ; Sherwin, W B
}

DOI: https://doi.org/10.1016/j.anbehav.2012.08.029

Posted at the Zurich Open Repository and Archive, University of Zurich ZORA URL: https://doi.org/10.5167/uzh-65230

Journal Article

Accepted Version

Originally published at:

Kopps, A M; Sherwin, W B (2012). Modelling the emergence and stability of a vertically transmitted cultural trait in bottlenose dolphins. Animal Behaviour, 84(6):1347-1362.

DOI: https://doi.org/10.1016/j.anbehav.2012.08.029 
1 Modelling the emergence and stability of a vertically transmitted cultural trait in

\section{2 bottlenose dolphins}

3

4 Anna M. Kopps ${ }^{\mathrm{a}, \mathrm{b}}$ \& William B. Sherwin ${ }^{\mathrm{a}}$

5

$6 \quad{ }^{a}$ Evolution \& Ecology Research Centre, School of Biological, Earth, and Environmental

7 Sciences, University of New South Wales

$8{ }^{\mathrm{b}}$ Anthropological Institute \& Museum, University of Zurich,

Corresponding author:

11 Anna M. Kopps

12 Evolution \& Ecology Research Centre

13 School of Biological Earth, and Environmental Sciences

14 University of New South Wales

15 Sydney

16 NSW 2052

17 Australia

18 Email anna.kopps@gmx.com

19 Fax +61293851558

20 Phone +61293852198

21 


\section{Abstract}

An apparently vertically, socially transmitted foraging specialisation ("sponging") in bottlenose dolphins (Tursiops sp.) is observed in two adjacent gulfs within Shark Bay, Western Australia, where sponging has possibly spread from independent innovations. We designed an individual-based model based on empirical data, to investigate the conditions (of learning fidelity, and fitness benefits for spongers) under which sponging could be established and maintained. Simulations show that sponging is unlikely to be established from a single innovation event but the probability increases with independent innovation events. Once established, however, it can be maintained in the absence of fitness benefits for spongers, if learning fidelity of daughters is virtually $100 \%$. Smaller learning fidelities can be compensated with fitness benefits for spongers, but these benefits must be 5\% and $10 \%$, respectively, to compensate for learning fidelities of $96.25 \%$ and $92 \%$. Furthermore, we estimated the time since the emergence of sponging by tracking the average pairwise relatedness among spongers over time and comparing it to empirical estimates. For the eastern gulf of Shark Bay, we show that sponging might have been in place for at least 120 years if it originated from a single innovation event. For comparison of vertical, social transmission to other trait acquisition methods, we ran simulations in which sponging was acquired solely by innovation or sponging was a genetic trait. In these simulations, sponging could be maintained but the genetic and empirical data did not match. Hence vertical social transmission is a more feasible mechanism to explain the spread of sponging.

Key words: bottlenose dolphin, dating, fitness benefit, individual based-model, innovation rate, learning fidelity, social learning, sponging, Tursiops sp.

Socially learnt behaviours influence many domains of life in numerous animal species (reviewed in Galef \& Laland 2005): predator avoidance (Cook \& Mineka 1989); courtship behaviour (Noad et al. 2000); migratory routes (O'Corry-Crowe et al. 1997) and a growing body of literature describes foraging strategies which seem to be transmitted vertically (i.e., from parent to offspring). The diets or foraging strategies of offspring have been shown to resemble their mother's in sea otters (Enhydra lutris, Estes et al. 2003), orangutans (Pongo pygmaeus wurmbii, Jaeggi et al. 2010) and bottlenose dolphins (Tursiops sp., Mann \& Sargeant 2003; Sargeant \& Mann 2009), which indicates vertical transmission, possibly by social learning (Galef \& Laland 2005).

Mathematical modelling shows that the establishment and maintenance of a socially transmitted trait is very unlikely if naïve individuals only learn from one cultural parent (Enquist et al. 2010). Reasons for this conclusion are, firstly, that cultural drift (Koerper \& Stickel 1980) - analogous to random genetic drift - is likely to eliminate new innovations and, secondly, that it is unrealistic to assume that social learning is perfect (i.e., not all observers learn the behaviour). Under these conditions, fitness benefits assigned to bearers of socially 
learnt traits must be very high in order to maintain the trait in the population (Enquist et al. 2010). Therefore, the frequency of trait bearers in the population would be expected to decrease over time and the trait would be lost. However, Enquist et al.'s (2010) modelling was rather generic, and further development would be possible, especially the addition of full stochasticity and use of values form real populations. Individual-based stochastic modelling would allow use of more biological details of the system.

\section{The Sponging Behaviour}

Despite the low likelihood predicted for vertically, socially transmitted behaviours to be established and maintained, at least one such behaviour ("sponging") has been established in each of the two gulfs of Shark Bay, Western Australia (Smolker et al. 1997; Mann et al. 2008; Bacher et al. 2010). A subset of the bottlenose dolphin population wears conical marine sponges on their rostra when apparently foraging along the seafloor (Smolker et al. 1997; Mann et al. 2008). This behaviour appears to be based on a pattern of vertical social transmission without apparent genetic determination (Krützen et al. 2005; Ackermann 2008; Mann et al. 2008; Bacher et al. 2010). Within each gulf, spongers share maternally inherited mitochondrial DNA (mtDNA) haplotypes, with one exception of a male sponger with a different haplotype in the eastern gulf (Krützen et al. 2005; Ackermann 2008). This male indicates that horizontal/oblique transfer or individual learning of sponging may occur very rarely (Krützen et al. 2005). Sponging haplotypes differ between the gulfs (Ackermann 2008), which suggests that either sponging has been established from two independent innovation events in each of the two gulfs of Shark Bay (Ackermann 2008) or else that other horizontal transmission has occurred. We do not know how stable the sponging behaviour is over long time periods in either of the gulfs. Sponging was first observed in the eastern gulf in 1984 (Smolker et al. 1992), shortly after launching the long-term study of bottlenose dolphins in Shark Bay (Connor \& Smolker 1985). Since then, 41 spongers have been identified in the eastern gulf of Shark Bay (Mann et al. 2008) and, since 2007, 40 spongers have been identified in the main study area in the western gulf (Useless Loop, Kopps 2012). Learning of sponging is not perfect in the eastern gulf: $91 \%$ of daughters and $25 \%$ of sons born to spongers sponge (Mann et al. 2008). Hereafter, we will refer to the probability that an offspring born to a sponger becomes a sponger as "learning fidelity". Based on the sample sizes reported in Mann et al. (2008), the binomial 95\% confidence levels around the 91\% learning fidelity for daughters are $59 \%$ to $100 \%$. Sponging is habitat-dependent and only observed in deep water (channels $>6 \mathrm{~m}$ in the eastern gulf, Sargeant et al. 2007; $>10 \mathrm{~m}$ in the western gulf, Tyne et al. 2012) where the majority of females sponge (Mann et al. 2008; Kopps 2012).

Because sponging appears to have been established and maintained once or more in Shark Bay, it appears that additional modelling is required. The next stage in advancing our understanding of the establishment and maintenance of vertical social transmission is to develop individual-based models informed by biological data, thus providing models with are specific to a species and context. Individual variation in attributes and experience results in stochastic processes which are difficult to approach by analytical models. Simulations are run 
on a time axis where individuals follow probability-based rules of reproduction, migration or other behaviours implemented in the simulation (DeAngelis \& Mooij 2005).

\section{Time of Emergence of Culture}

Modelling not only allows examination of the maintenance of sponging, but also estimation of the time since its establishment. It is difficult to date innovation events. Their low frequencies mean that, in wild populations, it is rather unlikely that innovation events will be witnessed. However, innovation and extinction of conventions (e.g., hand sniffing) have been documented in capuchin monkeys (Cebus capucinus), where these behaviours lasted for up to ten years (Perry et al. 2003). If innovations are not observed, they can be tentatively dated by indirect methods. Based on archaeological dating methods on stone tools or bones with cut marks, the emergence of hominid tool use was dated to 2.6 million years (Semaw et al. 2003). Excavated flaked stone assemblages that derive from chimpanzee (Pan troglodytes) nut cracking have proved that durable records can shed light into past activity (Mercader et al. 2002). The excavated site was dated to 3400 years, indicating that tool use in chimpanzee has been transmitted for more than 200 generations (Mercader et al. 2007).

Indirect dating is more difficult in aquatic habitats because it is difficult to find material evidence of historic tool use. However, modelling of pairwise genetic relatedness provides a tool for indirect estimation of the emergence time of a vertically transmitted trait. If there are no competing influences on relatedness, then genetic relatedness among spongers is expected to decline over time since the common sponging ancestor (Krützen et al. 2005). Spongers in the eastern gulf of Shark Bay are more related than expected by chance (Krützen et al. 2005). Therefore, it was suggested that sponging in the eastern gulf derived from a more recent innovation event than in the western gulf, where the spongers are not more related than the population average (Ackermann 2008). These relatedness estimates were based on average pairwise relatedness based on biparentally inherited microsatellite DNA. (e.g., Queller \& Goodnight 1989).

\section{This Study}

In this study, we used bottlenose dolphin field data on life history, behaviour, and genetics to build an individual-based model of establishment and maintenance of sponging in the eastern and western gulf of Shark Bay (Figure A1 in the Appendix). This included the examination of learning fidelity and fitness effects necessary for establishment and maintenance of sponging, and the likely time since establishment. By comparison with observed patterns in Shark Bay, we also investigated the possibility of horizontal transmission or multiple innovations. Based on the simulation, we addressed the following questions: (i) Under what conditions of vertical social transmission is sponging stable? (ii) How likely is it that sponging is established from a single innovation event? (iii) Are spongers biparentally more related than the population average? (iv) Can we estimate the time since the emergence of sponging based on average pairwise relatedness among spongers? (v) Can the actual 
number of spongers give information about the time since the emergence of sponging? (vi) How many spongers would we expect and how genetically related would they be if sponging is a genetic trait or only individually innovated?

\section{METHODS}

\section{The Model}

We built an individual-based model of a diploid, sexually reproducing dolphin population in Matlab R2010a (MathWorks). Simulations were run and then compared to empirical results from the eastern and western gulf of Shark Bay independently. The two populations are connected by high dispersal (number of migrants >>1, Crow \& Kimura 1970; Krützen et al. 2004b); however, the $110 \mathrm{~km}$ separation between the study sites has led to low, but significant, genetic differentiation between the gulfs (Krützen et al. 2004b). In Shark Bay, male and female dolphins are philopatric, with males extending their natal range (Tsai \& Mann 2012). Therefore, dispersal between the gulfs was not implemented in the model.

The population size was set to 600 at the start of the simulation. In three field seasons in the western gulf (Figure A1 in the Appendix) we identified almost 500 individuals, and unknown individuals have been encountered since (Kopps 2012). However, 500 dolphins is more than the $229 \pm 42$ dolphins estimated based on an aerial survey in 1994 for the study area in the western gulf of Shark Bay (Preen et al. 1997). The same survey estimated the number of dolphins in the study area in the eastern gulf to be $530 \pm 146$.

Virtual dolphins had the following attributes (Table A1 in the Appendix): a unique individual number, sex, age class, habitat, whether sponger or non-sponger (which could also represent any other maternally transmitted trait), mtDNA haplotype, and genotypes for ten neutral, polymorphic, biparentally inherited loci. Sex ratio at birth and at the start of the simulation was $1: 1$. During the simulation, the sex ratio was expected to fluctuate around a 1:1 ratio. The proportion of individuals in habitat 1 (deep) equalled the proportion of individuals in habitat 0 (shallow) at the start of simulations. In the western gulf of Shark Bay, $51 \%$ of the study site consists of deep habitat (Tyne et al. 2012) while $32 \%$ of the study site in the eastern gulf consist of channel habitat (Patterson, unpublished). Spongers in the eastern gulf of Shark Bay were sighted $84.1 \pm 2.8 \%$ and spongers in the western gulf $95.9 \%$ of times in deep (channel) habitat (Mann et al. 2008; Kopps 2012). Therefore our model assumed that habitat stayed constant over a virtual dolphin's life.

Simulations were run in cycles of 12-year time periods (Figure A2 in the Appendix). The maximum life span of an individual in the simulation was 36 years, thus it could be present for a maximum of three time periods. The oldest known Shark Bay female died at age 35 years, but life expectancies of up to 40 years would not be surprising (Mann et al. 2000). The 36 year maximum life span of virtual dolphins was split into three 12 year periods. In the first 12 year period (age class 1), dolphins were immature and did not reproduce. Females in Shark Bay usually give birth to their first calf when they are 12 years old or older (Mann et al. 
2000). Males do not usually reproduce successfully until they are allied (Krützen et al. 2004a; Kopps 2007), with alliances crystallising when males are around 12 years of age (Connor et al. 2000). After sexual maturity, the number of offspring an individual produces during a 12year time period was assigned from a Poisson distribution, with mature females ( $>12$ years old) having a mean of three calves during each 12 year period. In the eastern gulf of Shark Bay, the distribution of the number of offspring that a female can produce does not differ from a Poisson distribution (derived from Table 1 in Mann et al. 2000) and calves are on average weaned when they are 4 years old. If a calf dies, its mother resumes cycling quickly after calf loss (Mann et al. 2000). Reproductive success of dolphins in age classes 2 and 3 did not differ. Each of the three 12 year age classes was given a mortality rate $(0.48,0.28$ and 0.21 for age classes 1, 2 and 3 respectively), estimated from Stolen and Barlow (2003).

The mtDNA haplotype frequencies at the start of the simulation equalled the frequencies of the three main haplotypes observed in Useless Loop, the main study area in the western gulf of Shark Bay. The three main haplotypes represent $96 \%$ of haplotypes observed in the western gulf (Kopps 2012). Five haplotypes have been described for the main study area in the eastern gulf of Shark Bay (Krützen et al. 2004b).

Females and males from age class two and three were paired randomly in order to reproduce. Alleles of ten polymorphic loci were passed on from parent to offspring by Mendelian inheritance. The ten loci had on average 5.6 alleles/locus at the start of the simulations. This number is similar to that found in empirical studies of this population (Ackermann 2008). However, the expected heterozygosity (0.738 \pm 0.027 (mean \pm 1 SE)), was significantly higher in simulations than in empirical studies (Table A2 in the Appendix). Mutations were not implemented in the simulation because effects of mutations are negligible for the time frame over which the simulations were run (Ellegren 2000).

Sponging was vertically transmitted from mother to offspring, or sponging was acquired by innovation or by horizontal/oblique transmission. We did not differentiate between repeated innovations and horizontal learning because both mechanisms can lead to spongers with potentially different mtDNA haplotypes. We varied the relative frequency of these events. Other parameters we altered were the sponging learning fidelity of female offspring born to spongers (range 0.875 to 1 , in steps of 0.0125 ) and potential fitness benefits in the form of producing more offspring (range 0.975 to 1.2 , in steps of 0.025 ). We considered that 3 offspring per time period was a fitness of unity (i.e. the same as the average member of the population, as described above), leading to the following mean number of offspring (with corresponding fitness values shown in brackets): 2.925 (0.975), 3 (1), 3.075 (1.025), 3.15 (1.05), 3.225 (1.075), 3.3 (1.1), 3.375 (1.125), 3.45 (1.15), 3.525 (1.175) and 3.6 (1.2). The maximum fitness benefit was 1.2 because Mann et al. (2008) found a non-significant fitness advantage of 1.18 .

All simulations were run for 50 twelve-year time periods (which equals 600 years) and 100 independent iterations, if not otherwise stated. Abundance and genetic measures were taken every five time periods. For biparental relatedness, we implemented the Queller and 
Goodnight (1989) pairwise relatedness estimator which was previously used to estimate relatedness in empirical studies of sponging (Krützen et al. 2005; Ackermann 2008). We implemented a subsampling procedure to estimate average pairwise relatedness among spongers and of the whole population, because only a subset of the population was sampled in the empirical studies. A third of the virtual population was randomly chosen and the average pairwise relatedness of spongers in the subsample and the subpopulation was calculated. The subsampling procedure was repeated five times and the mean average relatedness among spongers and for the whole populations was calculated and then used in further analyses such as comparison with observed patterns in Shark Bay.

\section{Sponger Stability}

The first question we addressed using the simulation was: under what conditions of vertical transmission is sponging stable? We altered fitness benefits assigned to female spongers compared to non-sponger females, and the learning fidelity of daughters born to spongers. We specified that sons born to spongers acquired the sponging behaviour with a probability of $25 \%$ as in Mann et al. (2008). We chose a proportion of 0.1 females to be spongers at the start of the simulations because this is similar to the value in the eastern gulf of Shark Bay, where a proportion of 0.11 of the adult female population use sponges (Mann \& Sargeant 2003). Even though the proportion of adult female spongers in the western gulf is higher than 0.1 (0.37, Kopps 2012), we only ran the simulations with 0.1 female spongers because this is a more stringent case: there is a greater probability of loss of sponging at low frequencies, analogous to rare alleles in population genetics (Halliburton 2004).

Various combinations of learning fidelity and fitness benefits were chosen to investigate conditions under which sponging was or was not maintained. In order to assess whether the proportion of female spongers was constant in a population, we compared the start proportion of 0.05 in the population ( 0.1 of females) with the proportion of female spongers in the population after 50 time periods. If 0.05 was within 2 standard errors (SE) across iterations of the sponger proportion at the end of the simulation, then we concluded that the proportion of spongers was stable. Standard errors of the proportion of female spongers in the population $\left(\mathrm{SE}_{\mathrm{P}}\right)$ were calculated at the end of simulations using the following formulas, based on the standard method for combining variances (calculation of formulas is in the Appendix, based on Crow \& Kimura 1970):

$\sigma_{\mathrm{P}}^{2}=\sigma_{N} s^{2} / \mathrm{N}^{4}+\sigma_{\mathrm{s}} / N^{2}+2 \operatorname{Cov}(N, s)^{*} s / N^{3}$

$\mathrm{SE}_{\mathrm{P}}=\left(\sigma_{\mathrm{P}} / \mathrm{n}\right)^{0.5}$

where $\sigma_{\mathrm{P}}$ is the variance of the proportion of spongers, $s$ is the average number of spongers, $\sigma_{\mathrm{s}}$ its variance and $N$ the average population size, with variance $\sigma_{\mathrm{N}}$. Variances were calculated from $n=100$ iterations, after 50 time periods.

\section{Sponger Establishment}


The second question we addressed was: how likely is it that sponging is established from a single innovation event? We ran 100 iterations starting with one female sponger in a population of 600 virtual dolphins. After 50 time periods, we counted the number of iterations in which we observed at least one sponger. We used various parameter settings of daughter learning fidelity and female sponger fitness benefits. Because rare multiple innovation or horizontal/oblique transmission is possible, we repeated the analysis described above and introduced repeated innovations/horizontal learning with a chance to become a sponger of $0.001,0.005$ or 0.05 , for dolphins of deep habitat in each time period. We counted the number of cases in which there was more than one sponger haplotype at 50 time periods and we calculated haplotype frequencies of spongers.

\section{Relatedness and Time since Emergence}

The third question we addressed was: are spongers biparentally more related than the population average? We ran simulations starting with one female sponger and analysed the average pairwise relatedness $\left(\mathrm{R}_{\mathrm{QG}}\right.$, Queller \& Goodnight 1989) among spongers of 100 iterations in which spongers were present after 50 time periods. Various combinations of learning fidelity and fitness benefits were chosen. Additionally, we ran one simulation for 100 time periods. We only ran one simulation for 100 time periods because the rejection of iterations in which no spongers remained, and the way in which the calculation of pairwise relatedness was implemented, made this an extremely slow procedure computationally. However, this does not contradict our conclusion that sponging can persist.

The fourth question we addressed was: can we estimate the time since the emergence of sponging based on average pairwise relatedness among spongers? In order to estimate how long sponging has been present in each gulf of Shark Bay, we compared the simulation results over time to the average pairwise relatedness reported in empirical studies (Krützen et al. 2005; Ackermann 2008). The time since the emergence of sponging in a gulf was defined as the first time period in which the average pairwise relatedness among spongers reported in empirical studies was within 2 SE of the average pairwise relatedness among spongers in the simulation.

\section{Number of Spongers}

While running simulations, we noticed that the actual number of spongers observed in Shark Bay was rarely equalled in simulations. In the eastern gulf of Shark Bay, 41 spongers have been documented (Mann et al. 2008; another publication says 54, Patterson \& Mann 2011) while in the western gulf 54 spongers have been documented (Tyne et al. 2012). However, Tyne et al. (2012) used a different sponger definition to that used in the eastern gulf. For comparisons between gulfs we used the definition outlined in (Mann et al. 2008) and counted 40 spongers in the western gulf (Kopps 2012). The fifth question we addressed was whether the actual number of spongers can give information about the time since the emergence of sponging. We tracked the maximum number of spongers over all iterations over 
time and determined the probability of observing at least 40 spongers in the population. The probability was estimated by counting the number of iterations with 40 or more spongers (males and females).

\section{Alternative Acquisition Mechanisms}

It has been established that despite its vertical transmission sponging does not fit any simple genetic inheritance mechanism (Krützen et al. 2005; Bacher et al. 2010). Nevertheless, we ran simulations in which sponging was genetically transmitted or only individually innovated. We investigated how the proportion of spongers in the population and the number of spongers changed over time and what influence these alternative acquisitions of sponging have upon the genetic relatedness among spongers.

In scenarios in which sponging was a genetic trait, sponging was modelled as an additive single-locus trait expressed only in females, and only in certain environmental conditions. In other words, if a female lived in deep habitat and was homozygous for the "sponging allele", then she was a sponger. If she was heterozygous with one copy of the sponging allele she had a 50\% chance of being a sponger. Without any copies of the sponging allele, dolphins were never spongers. Females living in shallow habitat, and males in any habitat, were never spongers. We only considered cases in which the sponging locus was unlinked to the loci used to assess genetic relatedness. Simulations started with a single sponger - a female from the deep habitat which was homozygous for the sponging allele. No other sponging alleles were present in the population at the start of the simulation. Because the number of sponging alleles built up slowly over time we set an initial burnin period of 200 time periods before recording data. The population size was reset to 600 at 200 time periods. We only analysed runs in which at least one sponger was present between time periods 200 and 250. Simulations were run with three different values of fitness benefits for female spongers (i.e., 1, 1.075, 1.15) after a burnin period with fitness benefits of 1.15 . Running this scenario for 250 time periods did not take longer than running the vertical transmission scenario for 100 time periods because the sponging allele can also be transmitted by males and therefore it is more persistent than a uniparentally transmitted trait.

In simulations in which sponging was only individually innovated, dolphins of deep water habitat had the chance to innovate sponging in every time period with innovation rates of 0.025 or 0.05 . We added $5 \%, 10 \%$ and $15 \%$ fitness benefits for female spongers. We have not simulated horizontal transmission because this would require too many assumptions (e.g., who naïve individuals learn from) which is outside the scope of this manuscript.

\section{RESULTS}

\section{Sponger Stability}

The simulations show that an initial proportion of 0.05 female spongers in the population does not significantly change, under certain conditions of learning fidelity of daughters born to spongers, and fitness benefits for spongers compared to non-spongers (Figure 1). For example, if the learning fidelity equals 1 , there cannot be any fitness costs for 
spongers otherwise sponging will disappear. With lower learning fidelity, progressively higher fitness benefits are required for stability of the behaviour in the population. We will refer to simulation conditions in which the female sponger proportion in the population increased above the initial 0.05 as "favourable conditions" and conditions in which the female sponger proportion decreased below 0.05 as "unfavourable conditions".

[insert Figure 1]

\section{Sponger Establishment}

A vertically transmitted, sex-biased trait is unlikely to spread from a single innovation (Figure 2a). Chances of establishment increased with greater fitness benefits for trait bearers and with increased learning fidelity; however, the proportion of iterations in which sponging was retained after 50 time periods never rose above 15\%, when starting from a single sponger.

A chance of repeated innovation/horizontal learning of 0.001 per time period for females of deep habitat increased the probability of finding spongers after 50 time periods (Figure 2b). However, in this scenario, the mitochondrial DNA variation did not match the observed patterns in empirical studies. Starting from the haplotype frequencies observed in Useless Loop (Kopps 2012), by the end of the simulation more than one sponging haplotype co-occurred in $10 \%$ of iterations (under the following conditions: fitness benefits $=1$, learning fidelity $=1$ ). Increasing the rate of repeated innovations/horizontal transmission to 0.005 and 0.05 led to $42 \%$ and $93 \%$ of iterations with more than one co-occurring sponging mtDNA haplotype respectively at the end of simulations. In Figure 3, we plotted the proportion of the most common haplotype within simulated spongers. In the eastern gulf of Shark Bay, 93.8\% of spongers share the same mtDNA haplotype whereas in the western gulf $100 \%$ of spongers share the same mtDNA haplotype (Ackermann 2008). In simulations, a single sponger haplotype percentage of $93.8 \%$ or higher was observed in 91,59 and $15 \%$ of iterations with increasing occurrence of repeated innovation/horizontal transmission $(0.001,0.005,0.05$ respectively).

\section{[insert Figure 2]}

[insert Figure 3]

\section{Relatedness among Spongers}

When starting with only one sponger, on average, pairwise relatedness among spongers decreased with increasing time and levelled off at approximately $\mathrm{R}_{\mathrm{QG}}=0.04$ after 35 time periods without decreasing to the population average $\left(R_{\text {pop }}=-0.0047 \pm 0.0003\right.$, Figure $\left.4 a\right)$. The average pairwise relatedness decreased independently of learning fidelity and fitness benefits for spongers (Figure 4a, Figure A3 in the Appendix). The proportion of female spongers in the population did not reach 0.05 and was still increasing at 50 time periods even in runs with "unfavourable conditions" under which female sponger frequency is expected to decrease 
(Figure 1, Figure 4c, Figure A3 in the Appendix). In this context it is worth noting that only iterations in which at least one sponger was present were included in these analyses.

[insert Figure 4]

We ran one simulation for 100 time periods (i.e., 1200 years, Figure A5 in the Appendix). The average proportion of female spongers in the simulation just reached the proportion of female spongers in the population observed in the eastern gulf at 95 time periods. The average pairwise relatedness among spongers was higher than the population average during the entire simulation (i.e., $\pm 1 \mathrm{SE}$ of the average population relatedness never overlapped $\pm 1 \mathrm{SE}$ of the average sponger relatedness). However, towards 100 time periods, the gap between the two ranges $( \pm 1 \mathrm{SE})$ decreased to only 0.007 .

Adding repeated innovations/horizontal transmission into the model (frequency: 0.001 and 0.005) did not change the observation that relatedness among spongers levelled off at approximately $\mathrm{R}_{\mathrm{QG}}=0.04$ after 35 time periods (Figure 5). A frequency of repeated innovations/horizontal learning of 0.05 led to an average pairwise relatedness among spongers which levelled off at approximately $\mathrm{R}_{\mathrm{QG}}=0.01$, as well as to a greatly increased proportion of spongers after 50 time periods. The observed proportion of female spongers in the eastern gulf was reached after 25 time periods. The observed proportion of female spongers in the western gulf was not reached after 50 time periods.

[insert Figure 5]

\section{Time since Emergence of Sponging}

On the assumption that no other factors change the relatedness of spongers relative to the general population's relatedness, we can estimate time of the emergence of sponging, by comparing the average pairwise relatedness among spongers in simulations, with the empirical data reported for the western $\left(R_{\text {spongers }}=-0.0213, R_{\text {population }}=-0.0241\right)$ and eastern gulf of Shark Bay $\left(R_{\text {spongers }}=0.0680, R_{\text {population }}=-0.0049\right.$, Ackermann 2008). If all spongers are descendents from a single innovator, the relatedness observed in the eastern gulf of Shark Bay is within 2 SE of the simulated average pairwise relatedness among spongers after 10 to 15 time periods (Figure 4a). This equals a time span of 120 to 180 years. If we consider repeated innovations or horizontal learning of the sponging behaviour (frequency 0.001, 0.005 and 0.05$)$, then there is no change to the estimate of the time since emergence of sponging (Figure 5a).

The empirical average pairwise relatedness among spongers in the western gulf of Shark Bay was always below the average pairwise relatedness among spongers $( \pm 2 \mathrm{SE})$ in the simulation with or without repeated innovation/horizontal transmission. 
A second approach to estimate the time since the emergence of sponging is to track the

460

461

462

463

464

465

466

467

468

469

470

471

472

473

474

475

476

477

478

479

480

481

482

483

484

485

486

487

488

489

490

491

492

493

494

495

496

497

498

499

500 actual number of spongers through time. At the end of all simulations in which sponging was vertically, socially transmitted and which started with a single sponger and ran for 50 time periods, the average actual number of spongers (and the proportion of spongers in the population) did not reach the observed numbers reported in field studies. The first time we observed 40 spongers in at least one iteration was between 15 and 30 time periods (180 to 360 years, Figure 4b, Figure A4 in the Appendix). However, this is the time until the maximum number of spongers observed reached 40 and other iterations showed fewer spongers. The probability for observing 40 spongers after 15 to 30 time periods did not exceed 5\% and was still below $30 \%$ after 50 time periods (Figure 4d, Figure A4 in the Appendix).

If we consider repeated innovations/horizontal transmission at low frequencies (i.e., $0.001,0.005$, Figure 5), the time span until we observed at least 40 spongers and its probability did not change compared to simulations without repeated innovations/horizontal transmission. Repeated innovations/horizontal transmission of 0.05 did not decrease the time until at least 40 spongers were observed but increased the probability of observing 40 spongers at 50 time periods to $79 \%$ (Figure 5).

\section{Alternative Acquisition Mechanisms}

In scenarios in which sponging was a genetic trait, the proportion of spongers increased if there were fitness benefits for spongers but seemed to be stable if fitness did not differ between spongers and non-spongers (Figure 6). Average pairwise relatedness among spongers seemed to be stable around the population average independent of fitness benefits (Figure 6a). In simulations in which sponging was only individually innovated, the proportion of spongers was stable, fluctuating around more than half the set innovation rate because sponging could only be innovated in deep habitat (Figure 7). The average pairwise relatedness among spongers was never different from the population average. The distribution of mtDNA haplotypes within spongers did not differ compared to the distribution in the population.

[insert Figure 6]

[insert Figure 7]

\section{DISCUSSION}

Enquist et al. (2010) showed that conditions for stable vertical transmission from a single cultural parent exist, but are so restrictive as to be very unlikely. However in this study, we used a different modelling approach to show that there are conditions which allow stable vertical social transmission from a single cultural parent, and that these conditions are representative of a natural population in which vertical transmission is supported by genetic data. Our stochastic model did not always match all aspects of the natural population, such as relatedness levels. However, our modelling shows that once a vertically, uniparentally transmitted trait is established, it can be stable within a population under certain conditions of 
fitness benefits and learning fidelity. Furthermore, this is the first study that dates innovation of a vertically transmitted trait by using pairwise relatedness.

\section{Sponger Stability and Establishment}

We show that the empirical ranges of learning fidelity ( 0.91 for daughters) and fitness benefits (no significant fitness benefits (Mann et al. 2008)) overlap with the range of fitness benefits (0.975 to 1.2) and learning fidelity values (range 0.875 to 1 ) that allow stable persistence of sponging in our model. In the absence of fitness benefits, it appears that sponging is only a stable vertically transmitted foraging strategy if virtually all daughters of spongers adopt the behaviour (Figure 1). In the eastern gulf of Shark Bay, calving success does not differ significantly between sponging and non-sponging females, and the observed learning fidelity is 0.91 for daughters (Mann et al. 2008) and its $95 \%$ confidence levels are 0.59 to 1 . In our simulation, these conditions would lead to decreasing sponger abundance in the eastern gulf. If this is the case, the question remains why at least 41 dolphins sponge at present (Mann et al. 2008). It is possible that fitness benefits for spongers might not be detectable but still be present because the statistical power to measure fitness benefits is possibly low considering the slow life history of bottlenose dolphins. In the light of the confidence limits for learning fidelity of $59 \%$ to $100 \%$, it seems feasible that sponging could be a stable vertically transmitted trait, if both learning fidelity and fitness benefits were underestimated in the field. If both male and female offspring learnt sponging, the conditions under which sponging is stable would not be changed because the behaviour is only transmitted by the mother.

The establishment of sponging is unlikely if it spreads from a single innovation event. Cultural drift is a strong force counteracting the establishment of new sponging matrilines, even in the presence of fitness benefits and repeated innovation/horizontal transmission. In simulation scenarios in which repeated innovation/horizontal transmission occurred, some retention of sponging was observed. This finding is in agreement with Enquist et al. (2010)'s more deterministic modelling. As would be expected, the frequency of multiple co-occurring haplotypes in spongers increased with increasing frequency of repeated innovation/horizontal transmission.

The predicted co-occurrence of multiple sponger haplotypes is consistent with findings of empirical studies to a certain degree. Multiple sponging haplotypes have been observed: haplotypes of spongers differ between the eastern and western gulf of Shark Bay, and also within the eastern gulf there are two haplotypes for spongers (Ackermann 2008). Within spongers of the eastern gulf, the two haplotypes had frequencies of $94 \%$ and $6 \%$ respectively (Ackermann 2008). In simulations with repeated innovations/horizontal transmission of frequencies $0.001,0.005$ and 0.05 , however, one of the haplotypes reached $94 \%$ or higher in 91,59 and $15 \%$ of iterations, respectively. This suggests that repeated innovations/horizontal transmission occur at the most at low frequencies, probably lower than 0.005 . However, our results suggest that some low frequency of repeated innovation is vital for the stability of the 
sponging behaviour because it is unlikely that sponging persists from a single innovation event, in agreement with Enquist et al. (2010).

\section{Time since Emergence of Sponging}

Based on pairwise relatedness, we dated the emergence of sponging to 120 to 180 years ago for the eastern gulf of Shark Bay (Figure 4a). However, the average pairwise relatedness among spongers levelled off after 25 to 35 time periods (300 to 420 years), at approximately $\mathrm{R}_{\mathrm{QG}}=0.04$, and still did not differ from the empirical value observed in the eastern gulf of Shark Bay by more than $2 \mathrm{SE}$ at 50 time periods in some simulations. Furthermore, after 50 time periods ( 600 years), the observed proportion of 0.05 female spongers in the population had not been reached. Therefore, 120 to 180 years is a minimum estimate of how long sponging has been practised in the eastern gulf.

In the western gulf of Shark Bay, the average pairwise relatedness of spongers does not differ from the average pairwise relatedness of the population (Ackermann 2008). This observation is not consistent with simulation results. In simulations with and without repeated innovations/horizontal transmission, average pairwise relatedness among spongers levelled off above the population average.

It is possible that we overestimated the time since emergence of sponging in the eastern gulf. It is known that the average pairwise relatedness of a group decreases with increasing group size (Lukas et al. 2005). Comparing iterations at the same points in time, we observed a weak negative correlation between average pairwise relatedness of spongers and the number of spongers present. However, the correlation was not present under certain conditions (Table A3 in the Appendix). In simulations, the observed absolute number of spongers reported from the eastern and western gulf of Shark Bay was rarely reached. However, estimates of time since emergence of sponging based on maximum number of spongers show that it is unlikely (chance 5\%) to observe 40 spongers between time point 10 and 15 (120-180 years) and therefore it is unlikely that the time since emergence of sponging was overestimated based on pairwise relatedness. The first time point at which 40 spongers were observed in a single iteration was between 15 and 30 time periods (180-360 years). Thus the minimum estimate of the emergence of sponging combining both methods - pairwise relatedness and the maximum number of spongers - is 180 years for the eastern gulf of Shark Bay. This estimate equals about 8.5 generations based on the bottlenose dolphin generation time reported in Taylor et al. (2007). For the western gulf of Shark Bay, we can only estimate the emergence of sponging based on the actual number of spongers. The estimate would be, as in the eastern gulf, 15 to 30 time periods.

Under the assumptions that cultural drift leads to the extinction of the majority of vertically transmitted innovations and that sponging has been innovated more than once, it is likely that sponging has been innovated more times than have been recorded and then lost again. The two estimates of 180 years since emergence of sponging in the eastern gulf of Shark Bay, one based on pairwise relatedness and one based on the actual number of 
spongers, describe the minimum time sponging has been transmitted continuously potentially including low frequencies of repeated innovations/horizontal transmission. It is possible that dolphins had used sponges before, but these skills were lost due to stochastic processes.

\section{Alternative Acquisition Mechanisms}

Like vertical transmission, alternative acquisition methods such as repeated innovation/horizontal transmission or genetic inheritance can lead to persistent traits in a population. Potentially, these mechanisms are more stable than vertical transmission. Modelling individual innovation and genetic inheritance revealed that in these scenarios the empirical values of the proportion of female spongers from the eastern gulf of Shark Bay can be replicated (assuming that an innovation rate of 0.1 leads to a proportion of female spongers around 0.05). However, relatedness among spongers and the distribution of mtDNA haplotypes does not differ from the population average. These results do not match observation from field studies and corroborate the hypothesis that sponging is vertically transmitted in the vast majority of cases (Krützen et al. 2005; Ackermann 2008).

We could not replicate two observations from field studies with our simulations emanating from a single sponger and without repeated innovation or genetic transmission. The first observation is that the average proportion of female spongers in the population did not reach the observed proportion reported in field studies. The second observation is that the empirical value of the average pairwise relatedness among spongers from the western gulf of Shark Bay was never within 2 SE of simulated data. Simulations with repeated innovation show that repeated innovation leads to a higher proportion of spongers in the population and to a lower average pairwise relatedness among spongers (although still higher than the population average, Figure 5) compared to simulations without repeated innovations (Figure 4). However, as discussed above, in simulations with repeated innovation, the distribution of mtDNA haplotypes among spongers does not match the field observation that most spongers share an mtDNA haplotype within gulfs. Both the proportion of female spongers and the average pairwise relatedness in the western gulf, could potentially be replicated by a scenario that includes population substructure. For example dolphins with certain mtDNA haplotypes might be predestined to live in particular habitats (e.g., dolphins with haplotype E live in deep water). In this scenario, repeated innovation rates could be higher than the values we tested and yet spongers would still share mtDNA haplotypes because haplotypes within habitats are more homogenous. Indeed, in the western gulf of Shark Bay we find segregation between habitat and haplotypes (Kopps 2012). Dolphins may have learnt other behaviours than sponging from their mothers and thereby specialised to the habitat.

\section{Assessment of our Model}

Our individual based-model is realistic in many ways, but simplified in others. It is based on observed sponger frequencies and estimated (sub)population sizes, it simulates overlapping generations and takes into account variability in female (and male) reproductive 
success. However, in order to obtain results from runs that were not inordinately long, we had to simplify the model in some regards. For instance, the number of genetic markers, the number of alleles and allele frequencies differed between the empirical study and the simulation we present here (Table A 2 in the Appendix). However, the average population pairwise relatedness in the empirical and simulation studies were both just below zero (eastern gulf -0.0049 , western gulf -0.0241 (Ackermann 2008), simulation $-0.0047 \pm 0.0003$ (mean \pm 2 $\mathrm{SE}$ ), which indicates that the chosen markers are close to the theoretical population average of zero. The results of the individual-based model were stable over various conditions of learning fidelity and fitness benefits to spongers, thereby strengthening the conclusions of this study. Although only relatively narrow ranges of values for learning fidelity and fitness benefits are shown, other trials (data not shown) make it clear that lower values do not lead to stability, while higher values are either impossible (i.e., fidelity > 1) or unrealistic (fitness advantage $>1.2$ ).

In the future, certain improvements could be made to the model. We did not include the possibility that sponging could be frequency-dependent. For example, sponges grow slowly and if there are many spongers it could be difficult to find appropriate sponges. This would mean that sponging was beneficial in certain circumstances but not others, so that fitness benefits for spongers would not be constant over time and therefore the maximum number of spongers would be lower. However, we would not expect that the implementation of frequency dependence would change the conditions in which sponging is stable because in our simulations, the proportion of spongers does not reach the proportion observed in field studies when frequency dependent mechanisms are ignored and under scenarios with quite high fitness benefits. In our simulations, population size tended to increase with increasing number of time periods. A more accurate set of mortality rates and different mortality rates for males and females could possibly keep the population size constant over time. However, under conditions in which fitness benefits are absolute ("hard selection", Wallace 1968), the population size would be expected to increase. If resources restrict the population size in Shark Bay, and sponging leads to the exploitation of a new niche (Patterson \& Mann 2011), sponging could lower within-population foraging competition, which could lead to an increase in population size.

We combined innovation and horizontal transmission as a single mechanism of acquiring sponging non-vertically. In future simulations, repeated innovations and horizontal learning could be analysed separately. If the proportion of time a naïve individual spends with a sponger (e.g., half weight index (HWI, Cairns \& Schwager 1987)) correlates with the probability of acquiring a skill horizontally, horizontal transmission could be simulated based on HWI. In Shark Bay dolphins, HWI correlates with, and could thus be approximated by, maternal and pairwise relatedness and home range overlap (Frère et al. 2010), sex and age class (Smolker et al. 1992).

\section{CONCLUSIONS}


675 Cultural drift is a strong force controlling the fate of an innovation. However, once a 676 vertically transmitted trait such as sponging has been established it can be maintained under 677 certain conditions of fitness advantages and learning fidelities. Individual-based models are a 678 useful tool to investigate processes influenced by stochastics. Simulating relatedness among 679 spongers over time revealed that if sponging spread from a single innovation event in the 680 eastern gulf of Shark Bay, it might have been present for at least 180 years. The probability of 681 observing the number of spongers reported from field studies is below $5 \%$ after 180 years of 682 sponging. This indicates that 180 years is likely an underestimate of the time since emergence 683 of sponging. The results of the individual-based model were robust to a variation of 684 conditions of learning fidelity and fitness benefits - although both had to be at the high end of 685 their realistic ranges for sponging to be stable. Nevertheless, the mismatch of the average 686 pairwise relatedness in the western gulf of Shark Bay shows that the model may require 687 further sophistication, as described above.

\section{ACKNOWLEDGEMENTS}

690 This study was inspired by work which will be published elsewhere and which was funded by

691 Sea World Research and Rescue Foundation, National Geographic Society, Claraz-

692 Schenkung, A.-H. Schultz Stiftung and Julius-Klaus Stiftung (grants to Michael Krützen, Lars 693 Bejder and WS). We would like to thank Janet Mann, Eric Patterson, Simon Allen and three 694 anonymous reviewers for their helpful comments. AMK was supported by a UNSW

695 University International Postgraduate Award and by the E\&ERC.

696

697 
Ackermann, C. 2008. Contrasting vertical skill transmission patterns of a tool use behaviour in two groups of wild bottlenose dolphins (Tursiops sp.), as revealed by molecular genetic analyses. MSc thesis. Anthropological Institute and Museum. University of Zurich. Bacher, K., Allen, S., Lindholm, A., Bejder, L. \& Krützen, M. 2010. Genes or Culture: Are Mitochondrial Genes Associated with Tool Use in Bottlenose Dolphins (Tursiops sp.)? Behavior Genetics, 40, 706-714.

Cairns, S. J. \& Schwager, S. J. 1987. A comparison of association indices. Animal Behaviour, 35, 1454-1469.

Connor, R. C. \& Smolker, R. S. 1985. Habituated Dolphins (Tursiops-Sp) in Western Australia. Journal of Mammalogy, 66, 398-400.

Connor, R. C., Wells, R. S., Mann, J. \& Read, A. J. 2000. The bottlenose dolphin: social relationships in a fission-fusion society. In: Cetacean societies (Ed. by J. Mann, R. C. Connor, P. L. Tyack \& H. Whitehead), pp. 91-126. Chicago: University of Chicago Press.

Cook, M. \& Mineka, S. 1989. Observational conditioning of fear to fear-relevant and fearirrelevant stimuli in rhesus monkeys. Journal of Abnormal Psychology, 98, 448-459. Crow, J. F. \& Kimura, M. 1970. An introduction to population genetics theory. New York: Harper \& Row.

DeAngelis, D. L. \& Mooij, W. M. 2005. Individual-Based Modeling of Ecological and Ellegren, H. 2000. Microsatellite mutations in the germline: implications for evolutionary inference. Trends in Genetics, 16, 551-558.

Enquist, M., Strimling, P., Eriksson, K., Laland, K. N. \& Sjöstrand, J. 2010. One cultural parent makes no culture. Animal Behaviour, 79, 1135-1162. prey selection by sea otters: patterns, causes and implications. Journal of Animal Ecology, 72, 144-155.

Frère, C. H., Krützen, M., Mann, J., Watson-Capps, J. J., Tsai, Y. J., Patterson, E. M., biparental kinship drive female associations in bottlenose dolphins. Animal Behaviour, 80, 481-486.

Galef, B. G. \& Laland, K. N. 2005. Social Learning in Animals: Empirical Studies and Theoretical Models. BioScience, 55, 489-499.

Halliburton, R. 2004. Introduction to Population Genetics. Upper Saddle River: Pearson Prentice Hall.

Jaeggi, A. V., Dunkel, L. P., Van Noordwijk, M. A., Wich, S. A., Sura, A. A. L. \& Van Schaik, C. P. 2010. Social learning of diet and foraging skills by wild immature Bornean orangutans: implications for culture. American Journal of Primatology, 72, 62-71. Journal of Anthropological Research, 36, 463-469. 
Kopps, A. M. 2012. Ecological, social and genetic forces shaping behavioural variation in bottlenose dolphins. PhD thesis. School of Biological, Earth and Environmental Sciences. University of New South Wales.

Krützen, M., Barre, L. M., Connor, R. C., Mann, J. \& Sherwin, W. B. 2004a. 'O father: where art thou?' - Paternity assessment in an open fission-fusion society of wild bottlenose dolphins (Tursiops sp.) in Shark Bay, Western Australia. Molecular Ecology, 13, 1975-1990. Krützen, M., Mann, J., Heithaus, M. R., Connor, R. C., Bejder, L. \& Sherwin, W. B. 2005. Cultural transmission of tool use in bottlenose dolphins. Proceedings of the National Academy of Sciences of the United States of America, 102, 8939-8943.

Krützen, M., Sherwin, W. B., Berggren, P. \& Gales, N. 2004b. Population structure in an inshore cetacean revealed by microsatellite and mtDNA analysis: Bottlenose dolphins (Tursiops sp.) in Shark Bay, Western Australia. Marine Mammal Science, 20, 28-47. Lukas, D., Reynolds, V., Boesch, C. \& Vigilant, L. 2005. To what extent does living in a group mean living with kin? Molecular Ecology, 14, 2181-2196.

Mann, J., Connor, R. C., Barre, L. M. \& Heithaus, M. R. 2000. Female reproductive success in bottlenose dolphins (Tursiops sp.): life history, habitat, provisioning, and groupsize effects. Behavioral Ecology, 11, 210-219.

Mann, J. \& Sargeant, B. L. 2003. Like mother, like calf: The ontogeny of foraging traditions in wild Indian Ocean bottlenose dolphins (Tursiops sp.). In: The biology of traditions: models and evidence (Ed. by D. Fragaszy \& S. Perry), pp. 236-266. Cambridge: Cambridge University Press.

Mann, J., Sargeant, B. L., Watson-Capps, J., Gibson, Q. A., Heithaus, M. R., Connor, R. C. \& Patterson, E. 2008. Why do dolphins carry sponges? PLoS ONE, 3.

Mercader, J., Barton, H., Gillespie, J., Harris, J., Kuhn, S., Tyler, R. \& Boesch, C. 2007. 4,300-Year-old chimpanzee sites and the origins of percussive stone technology. Proceedings of the National Academy of Sciences, 104, 3043-3048.

Mercader, J., Panger, M. \& Boesch, C. 2002. Excavation of a Chimpanzee Stone Tool Site in the African Rainforest. Science, 296, 1452-1455.

Noad, M. J., Cato, D. H., Bryden, M. M., Jenner, M. N. \& Jenner, K. C. S. 2000. Cultural revolution in whale songs. Nature, 408, 537-537.

O'Corry-Crowe, G. M., Suydam, R. S., Rosenberg, A., Frost, K. J. \& Dizon, A. E. 1997. Phylogeography, population structure and dispersal patterns of the beluga whale Delphinapterus leucas in the western Nearctic revealed by mitochondrial DNA. Molecular Ecology, 6, 955-970.

Patterson, E. M. \& Mann, J. 2011. The Ecological Conditions That Favor Tool Use and Innovation in Wild Bottlenose Dolphins (Tursiops sp.). PLOS ONE, 6, e22243.

Perry, S., Baker, M., Fedigan, L., Gros-Louis, J., Jack, K., MacKinnon, K. C., Manson, J. H., Panger, M., Pyle, K. \& Rose, L. 2003. Social Conventions in Wild White-faced Capuchin Monkeys: Evidence for Traditions in a Neotropical Primate. Current Anthropology, 44, 241-268.

Preen, A. R., Marsh, H., Lawler, I. R., Prince, R. I. T. \& Shepherd, R. 1997. Distribution and abundance of dugongs, turtles, dolphins and other Megafauna in Shark Bay, Ningaloo Reef and Exmouth Gulf, Western Australia. Wildlife Research, 24, 185-208. 
Queller, D. C. \& Goodnight, K. F. 1989. Estimating Relatedness Using Genetic-Markers.

786 Evolution, 43, 258-275.

787 Sargeant, B. L. \& Mann, J. 2009. Developmental evidence for foraging traditions in wild 788 bottlenose dolphins. Animal Behaviour, 78, 715-721.

789 Sargeant, B. L., Wirsing, A. J., Heithaus, M. R. \& Mann, J. 2007. Can environmental 790 heterogeneity explain individual foraging variation in wild bottlenose dolphins (Tursiops sp.)?

791 Behavioral Ecology and Sociobiology, 61, 679-688.

792 Semaw, S., Rogers, M. J., Quade, J., Renne, P. R., Butler, R. F., Dominguez-Rodrigo, 793 M., Stout, D., Hart, W. S., Pickering, T. \& Simpson, S. W. 2003. 2.6-Million-year-old 794 stone tools and associated bones from OGS-6 and OGS-7, Gona, Afar, Ethiopia. Journal of 795 Human Evolution, 45, 169-177.

796 Smolker, R., Richards, A., Connor, R., Mann, J. \& Berggren, P. 1997. Sponge carrying by 797 dolphins (Delphinidae, Tursiops sp.): A foraging specialization involving tool use? Ethology, 798 103, 454-465.

799 Smolker, R. A., Richards, A. F., Connor, R. C. \& Pepper, J. W. 1992. Sex-Differences in 800 Patterns of Association among Indian-Ocean Bottle-Nosed Dolphins. pp. 38-69.

801 Stolen, M. K. \& Barlow, J. 2003. A model life table for bottlenose dolphins (Tursiops 802 truncatus) from the Indian River Lagoon system, Florida, U.S.A. Marine Mammal Science, 803 19, 630-649.

804 Taylor, B. L., Chilvers, S. J., Larese, J. \& Perrin, W. F. 2007. Generation length and 805 percent mature estimates for IUCN assessments of cetaceans. La Jolla (CA): National Marine 806 Fisheries Service, Southwest Fisheries Science Center.

807 Tsai, Y.-J. J. \& Mann, J. 2012. Dispersal, philopatry, and the role of fission-fusion 808 dynamics in bottlenose dolphins. Marine Mammal Science, no-no.

809 Tyne, J., Loneragan, N., Kopps, A. M., Allen, S. J., Krützen, M. \& Bejder, L. 2012.

810 Ecological characteristics contribute to sponge distribution and tool use in bottlenose dolphins 811 (Tursiops sp.). Marine Ecology Progress Series, 444, 143-153.

812 Wallace, B. 1968. Topics in population genetics. New York: W. W. Norton. 


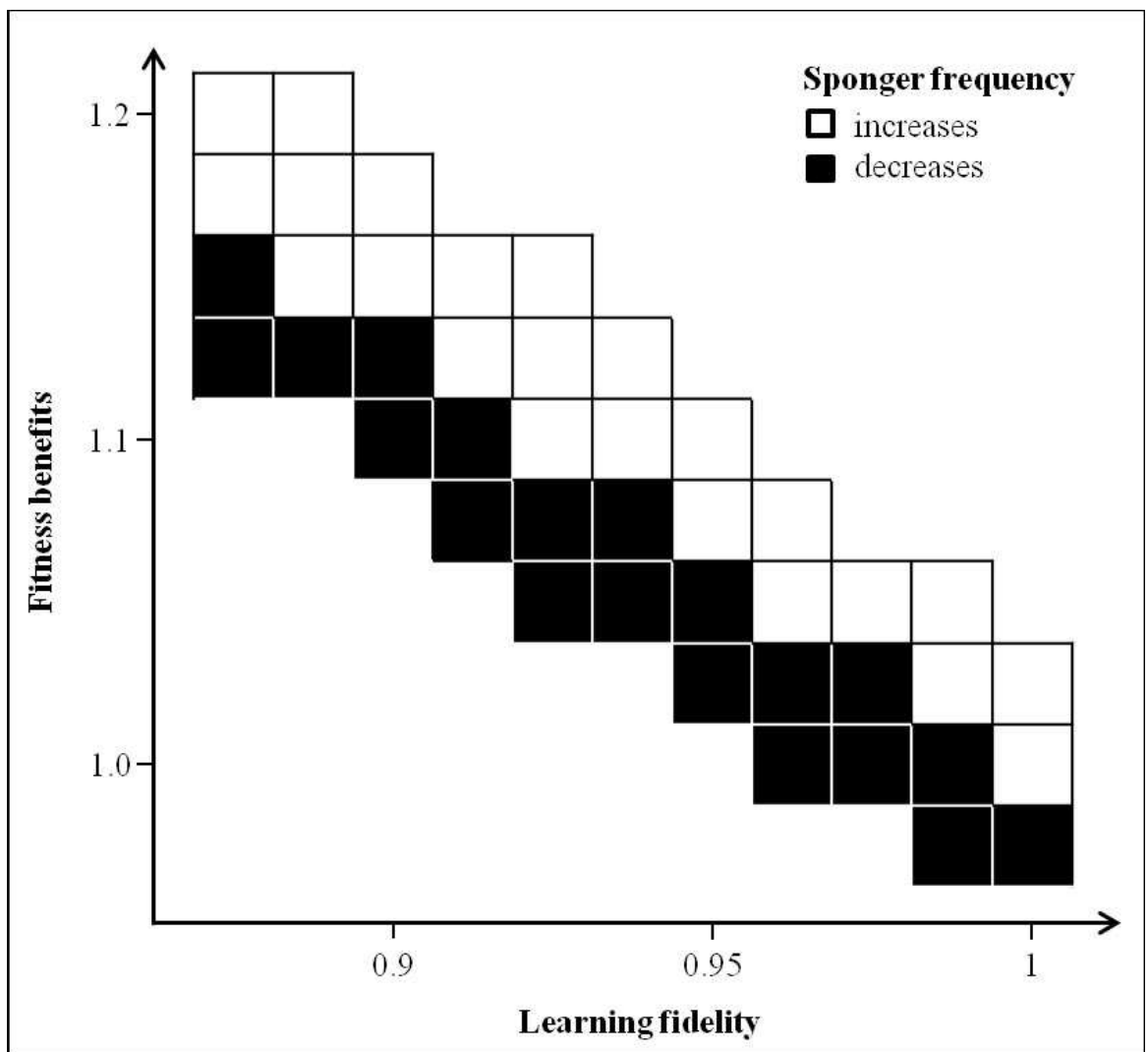

Figure 1: Stability of female sponger frequency under different conditions of learning fidelity of daughters and fitness benefits for spongers. Every square represents one run of a simulation with 100 iterations (leading to 43 runs with different combinations of learning fidelity and fitness benefits with 11 different values of learning fidelity from 0.875 to 1 , and 11 different values of fitness benefits from 0.975 to 1.2 ). The coordinates of the centres of the squares show the input parameters for learning fidelity and for sponger fitness benefits compared to non-sponger females. White squares: sponger frequency increases ("favourable conditions"); black squares: sponger frequency decreases ("unfavourable conditions").
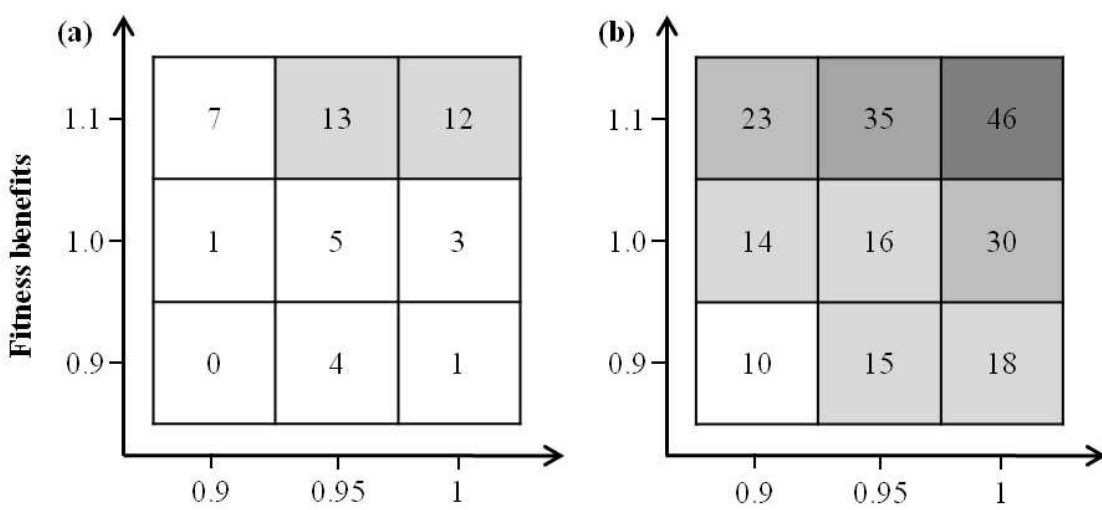
$\%$ of iterations with spongers $0-10$
(1) $11-20$
$21-30$
- $31-40$
$\square>40$

Learning fidelity

Figure 2: Sponger establishment. Percentage of iterations with proportion of spongers above zero at 50 time periods (a) starting from one sponger and (b) starting from one sponger with a frequency of repeated innovations/horizontal learning of 0.001/time period for females of deep habitat. Every square represents one run of a simulation with 100 iterations. Coordinates of the centres of the squares show the input parameters: learning fidelity and sponger fitness 
831
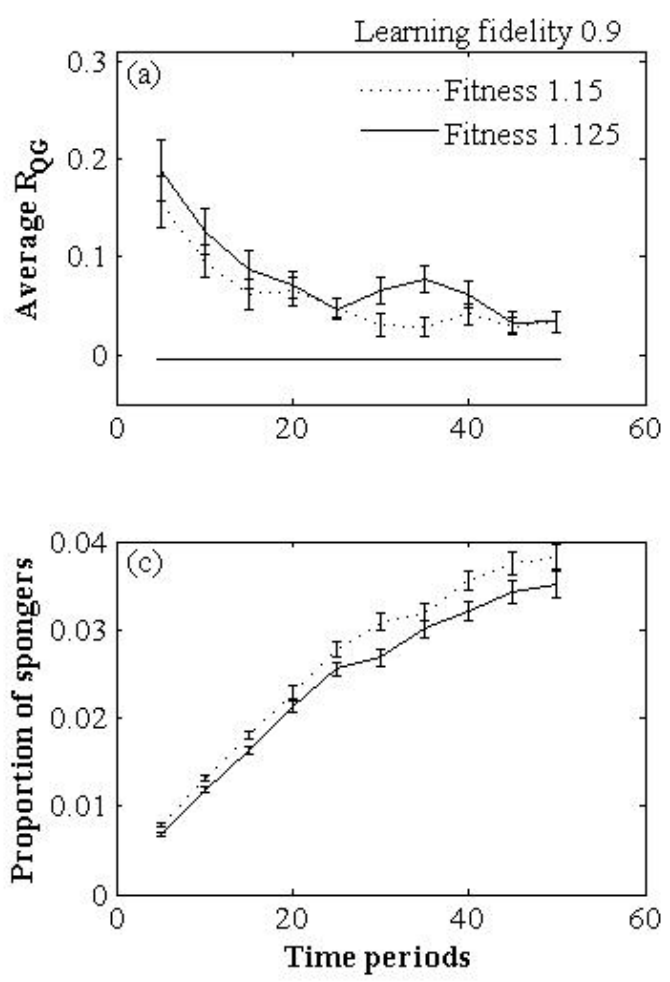

benefits compared to other females. Numbers in the squares are the number of iterations (of a total of 100 iterations) in which spongers were present at after 50 time periods.
832

833

834

835

836
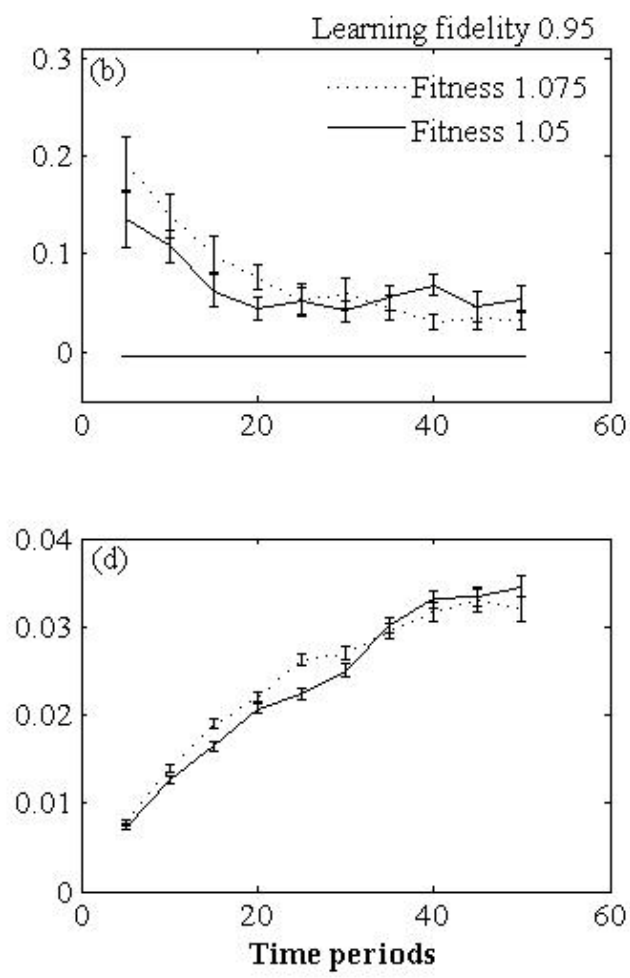

Figure 3: Histogram of the haplotype with the highest frequency within spongers at 50 time periods (fitness benefits 1 , learning fidelity 1 ). Rate of repeated innovation/horizontal transmission: (a) 0.001, (b) 0.005, (c) 0.05 . 

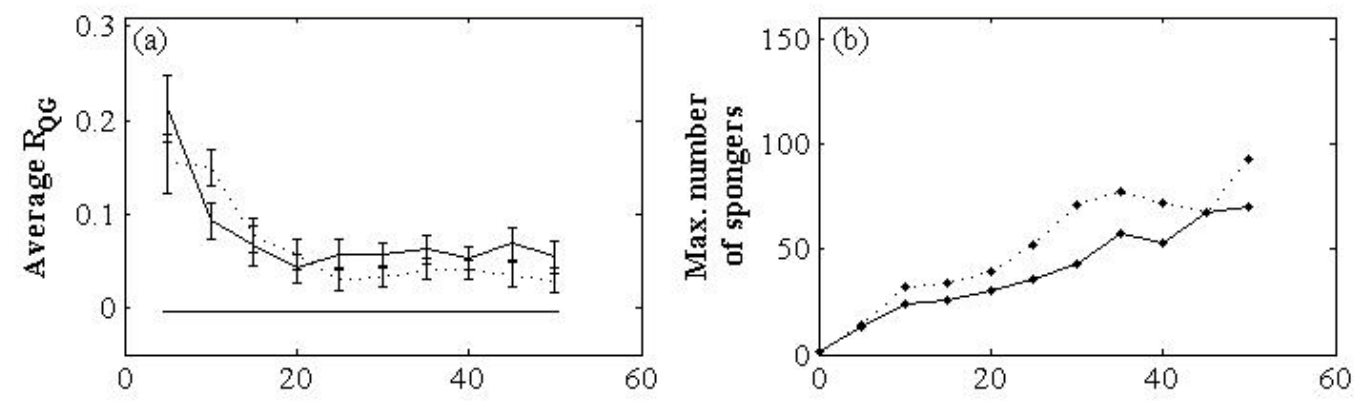

837
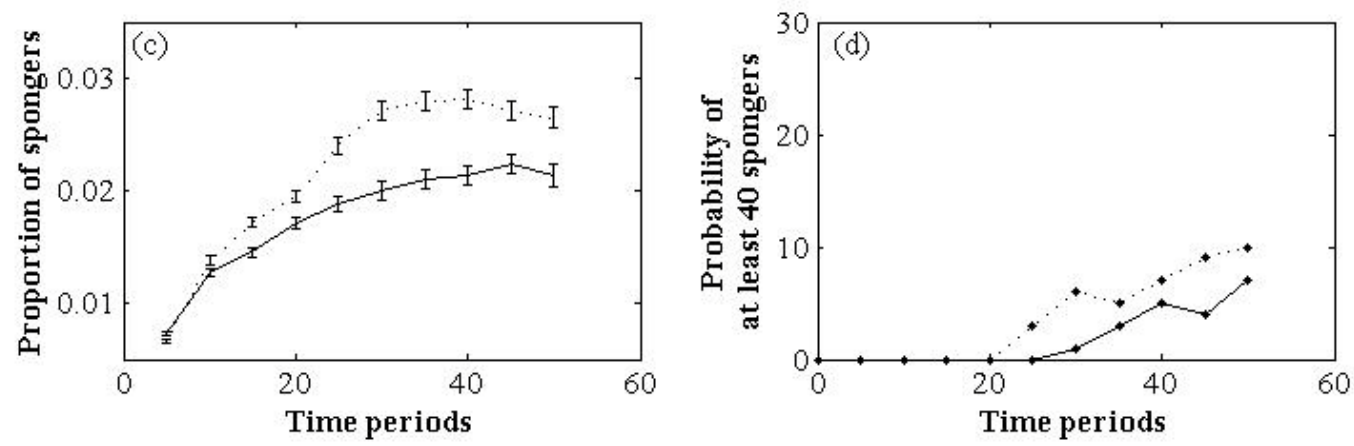

838 Figure 4: (a) Average pairwise relatedness among spongers, (b) actual maximum number of

839 spongers, (c) proportion of female spongers within the population and (d) the probability (\%)

840 to observe at least 40 spongers over time. Simulations started with a single sponger $(\mathrm{N}=100$

841 iterations in which at least one sponger was present in each time period). The horizontal line

842 in (a) represents the population average relatedness. Error bars represent \pm 1 SE. Dashed lines

843 indicate an example of a simulation with "favourable conditions" (learning fidelity 1, fitness

844 benefits 1) and solid lines indicate an example of a simulation with "unfavourable conditions"

845 (learning fidelity 1 , fitness benefits 0.975 ). 

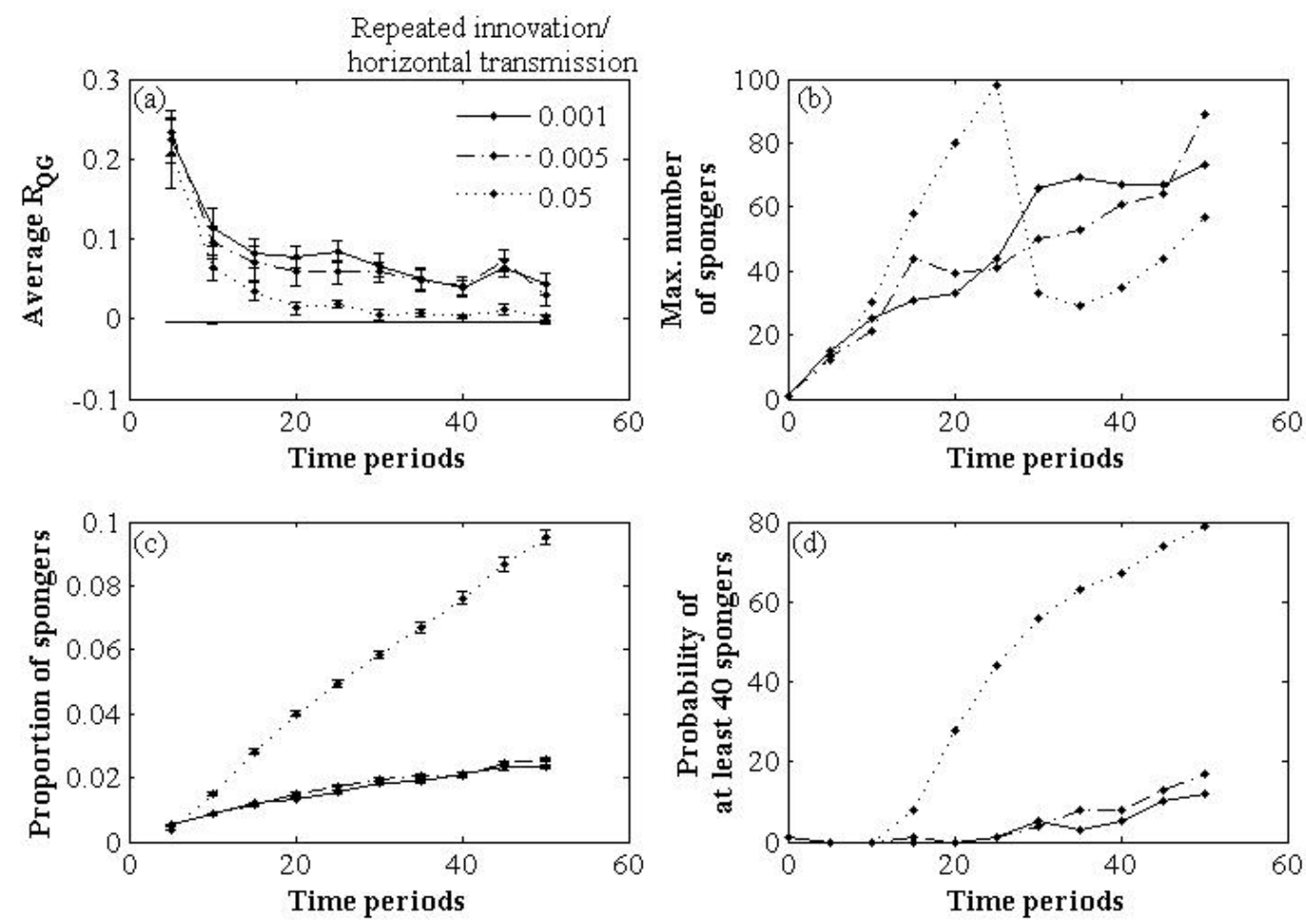

847

Figure 5: Influence of repeated innovations/horizontal learning on the average pairwise relatedness (Average $\mathrm{R}_{\mathrm{QG}}$ ) among spongers (a), the maximum number of spongers (b), the proportion of female spongers in the population (c), and the probability (\%) of observing at least 40 spongers in a population over time (d). For these three runs, fitness benefits and learning fidelity for spongers were set to 1 (favourable conditions). Error bars represent \pm 1SE. The horizontal line in (a) represents the population's average pairwise relatedness \pm 1SE.
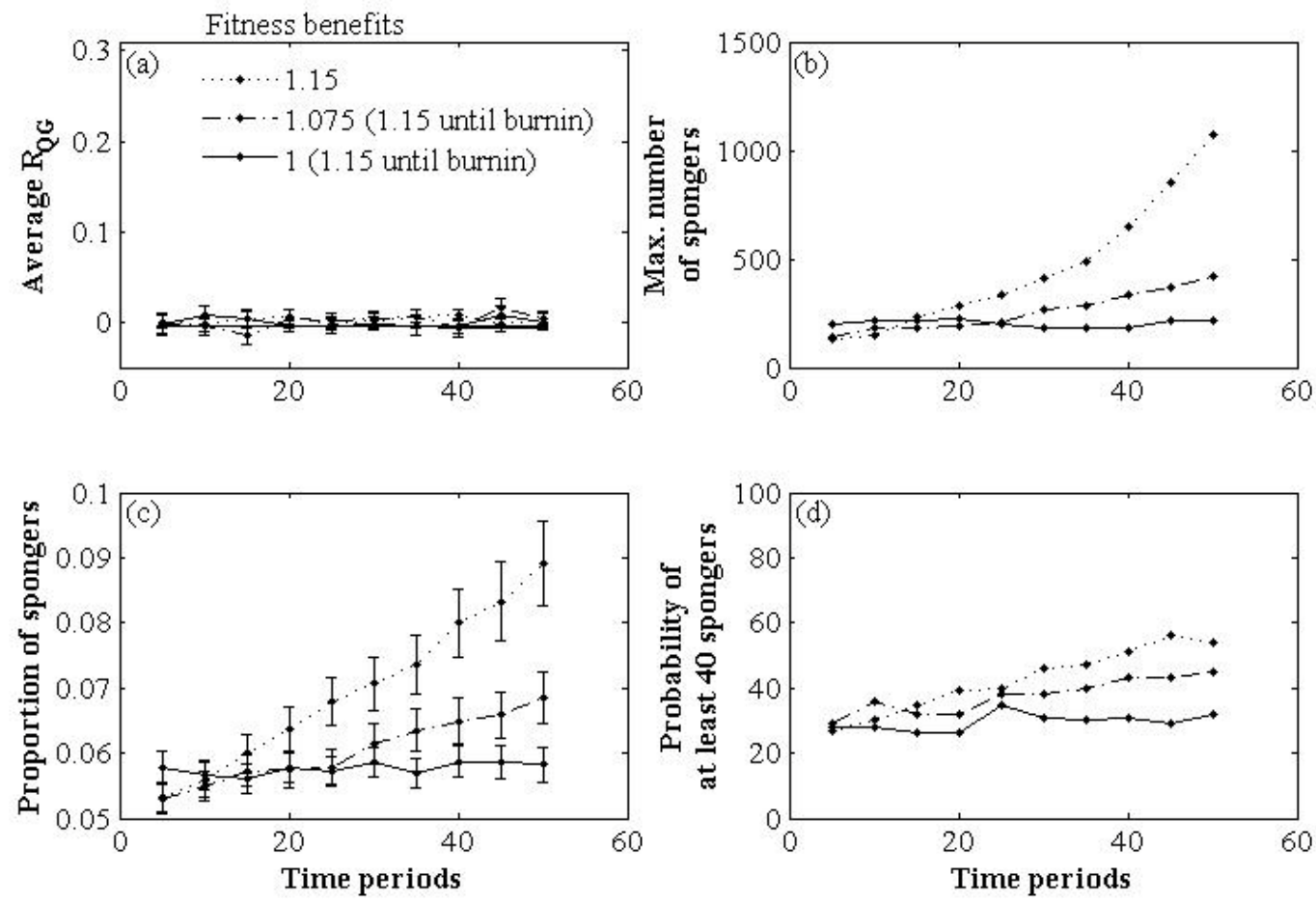
857 Figure 6: Sponging as an additive genetic, single locus trait and its influence on the average 858 pairwise relatedness (Average $\mathrm{R}_{\mathrm{QG}}$ ) among spongers (a), the maximum number of spongers

859 (b), the proportion of female spongers in the population (c), and the probability (\%) of 860 observing at least 40 spongers in a population over time (d). Note that data was only collected 861 after an initial burnin of 200 time periods in which the number of sponging alleles could build up.
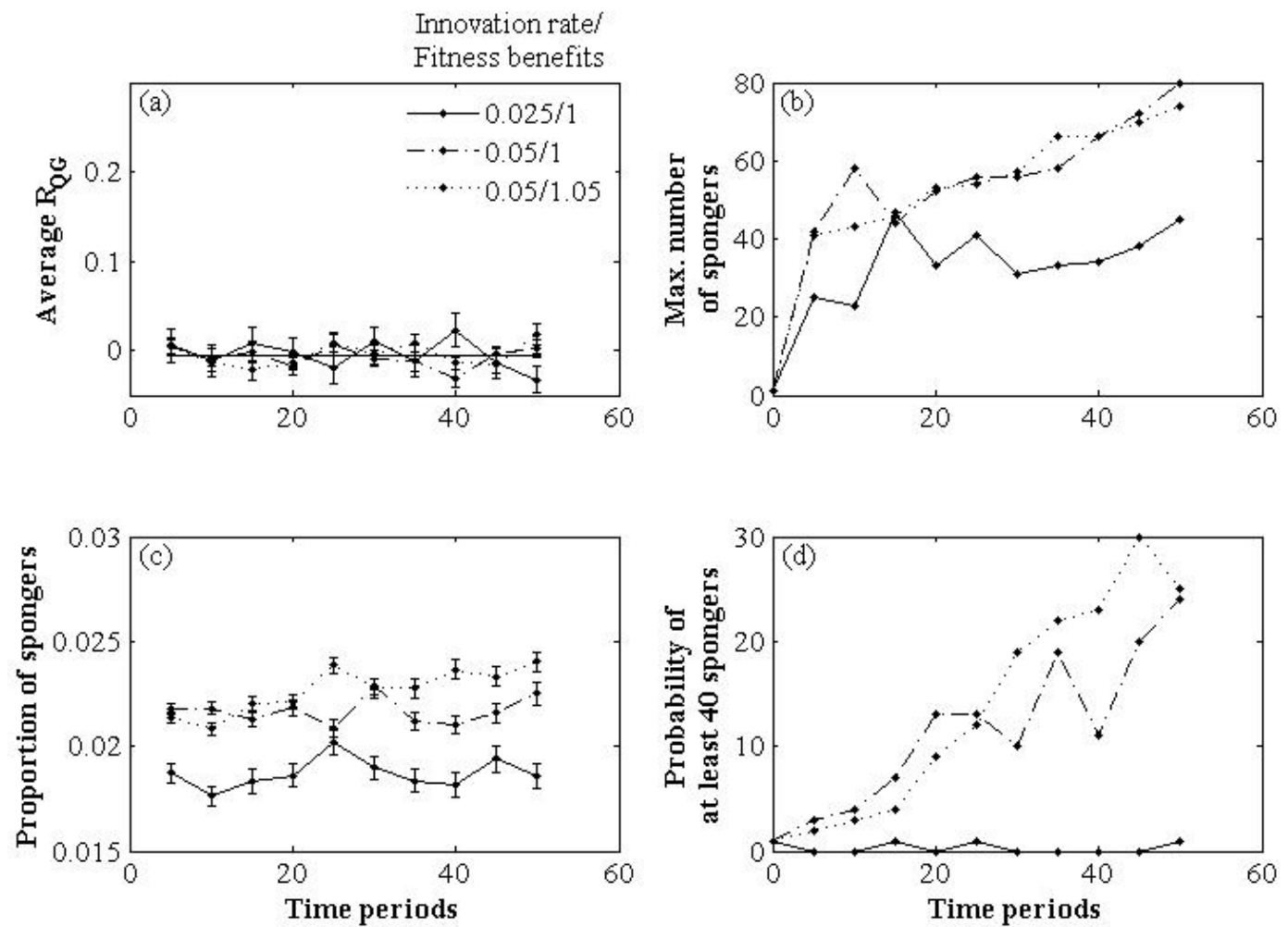

864

865

866

867

868

869

870

Figure 7: Sponging as an individually innovated trait and its influence on the average pairwise relatedness (Average $\mathrm{R}_{\mathrm{QG}}$ ) among spongers (a), the maximum number of spongers (b), the proportion of female spongers in the population (c), and the probability (\%) of observing at least 40 spongers in a population over time (d). Runs with higher fitness benefits are shown in the Appendix in Figure A6. 


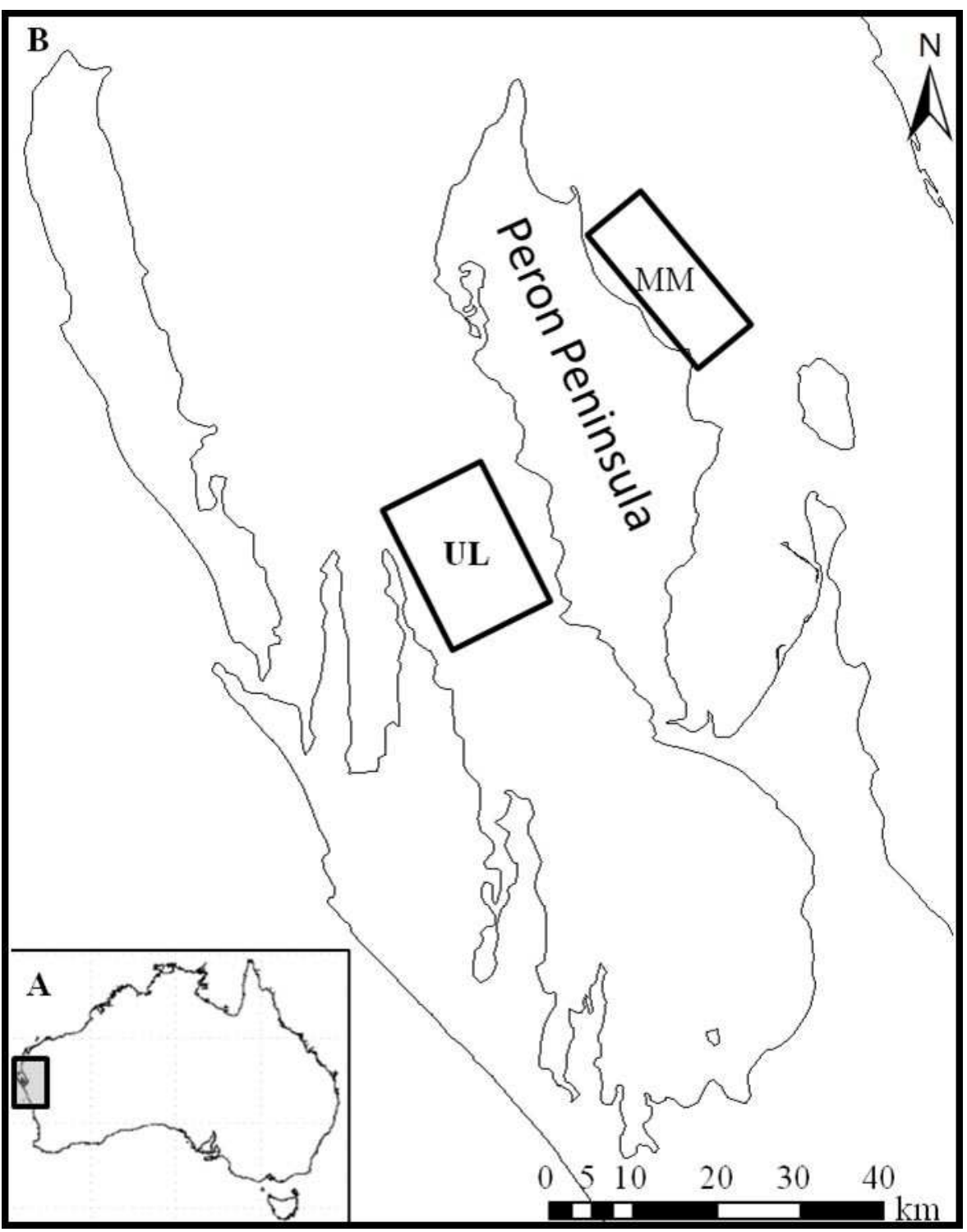

872 Figure A1: Map of Shark Bay. A Location of Shark Bay in Australia. B the main study sites 873 in the eastern (MM) and western (UL) gulf of Shark Bay. 


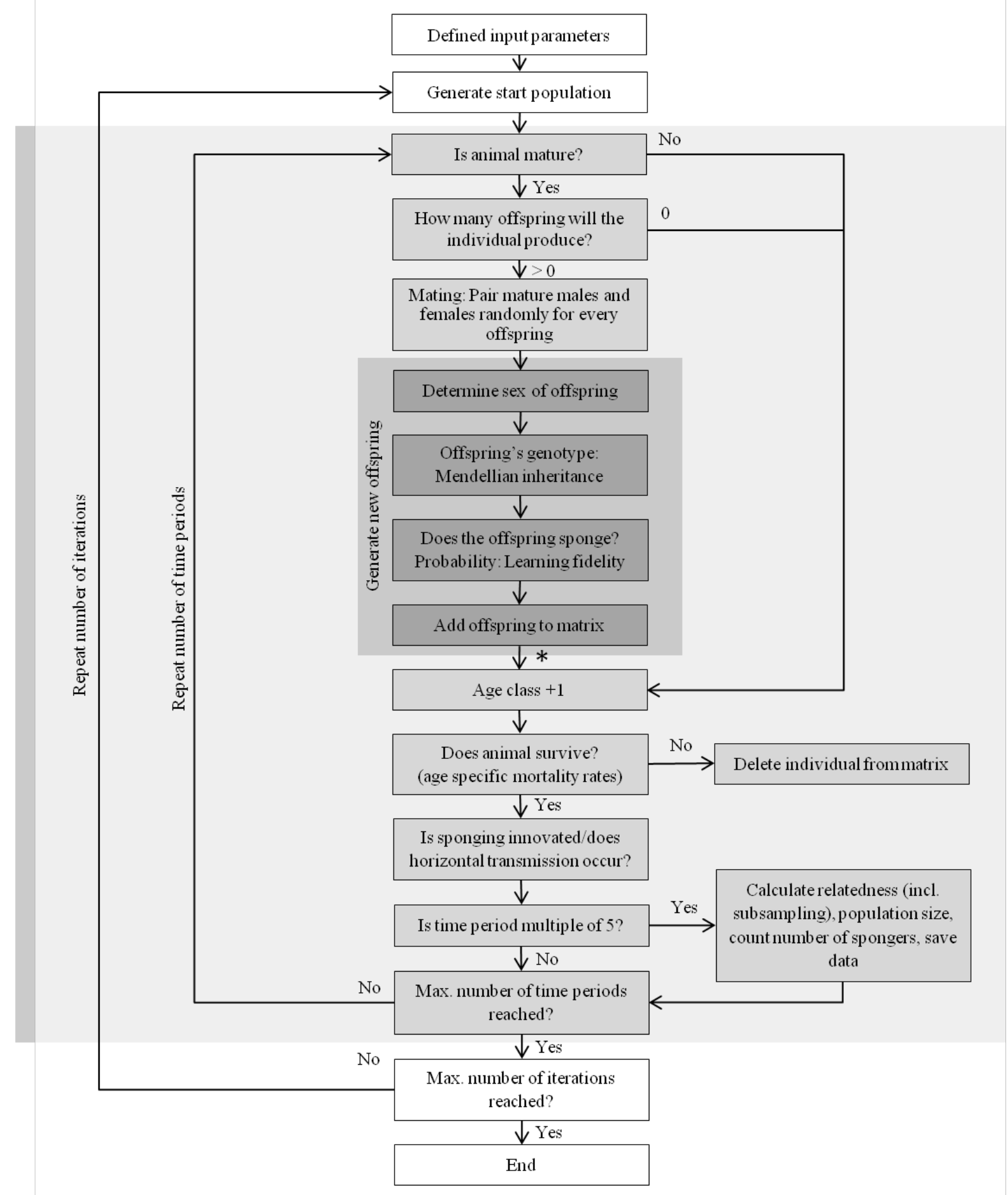

876 Figure A2: Flowchart of simulation. Input parameters included number of spongers,

877 frequency of repeated innovation/horizontal transmission, learning fidelity, fitness benefits for 878 spongers and the number of time periods the simulation was run for. An example of an input 879 matrix is shown in Appendix Table A1. * includes parents and offspring after this point. 

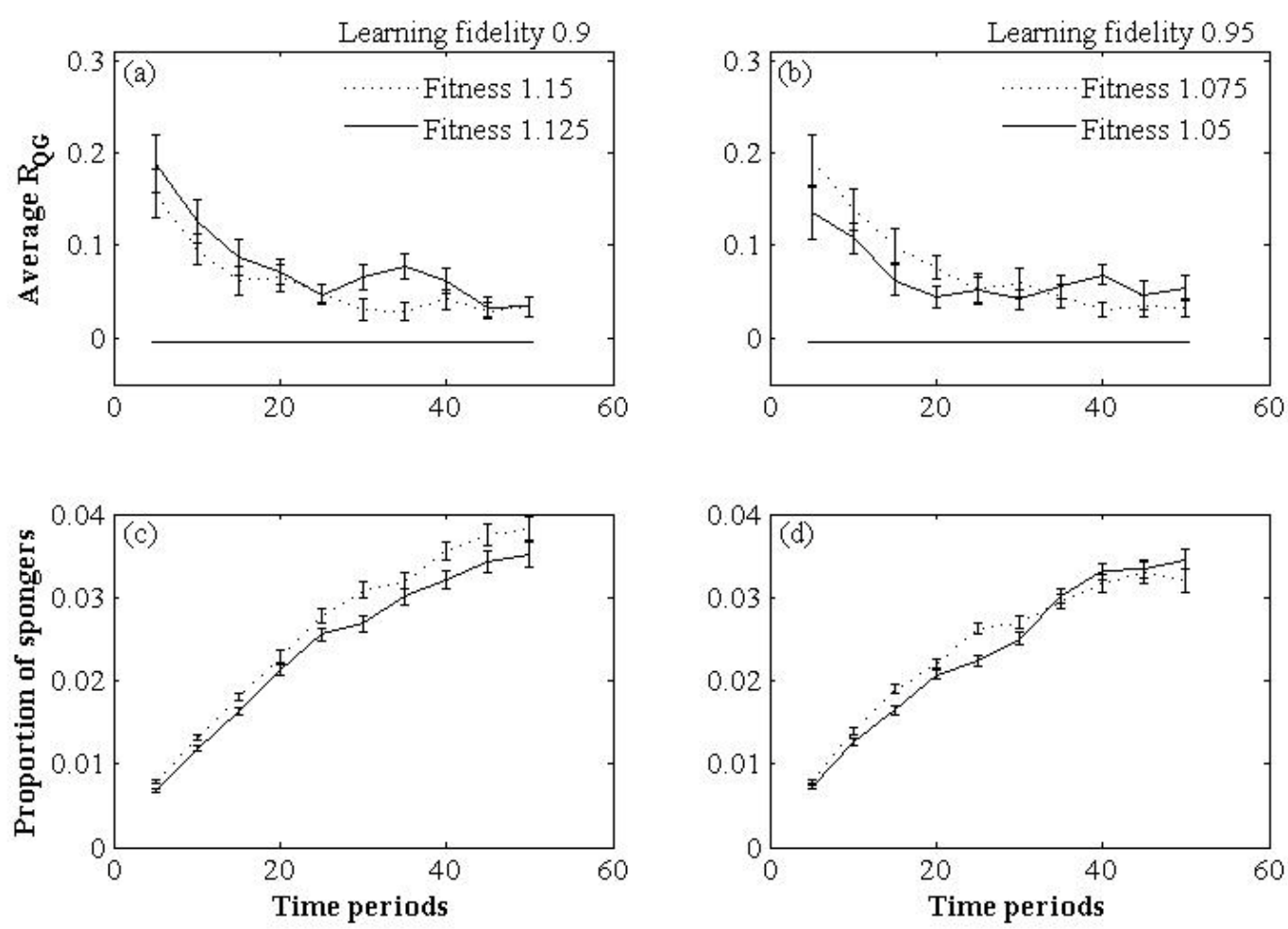

881

882 Figure A3: Average pairwise relatedness among spongers ((a) and (b)) and proportion of female spongers within the population over time ((c) and (d)). Simulations started with a 884 single sponger $(\mathrm{N}=100$ iterations in which at least one sponger was present in each time 885 period). (a) and (b): average pairwise relatedness over time ( $\pm 1 \mathrm{SE}$ ). Dashed lines indicate simulations with "favourable conditions" and solid lines indicate simulations with "unfavourable conditions". The solid line in (a) and (b) which equals approximately 0 is the population's average pairwise relatedness \pm 1 SE. 

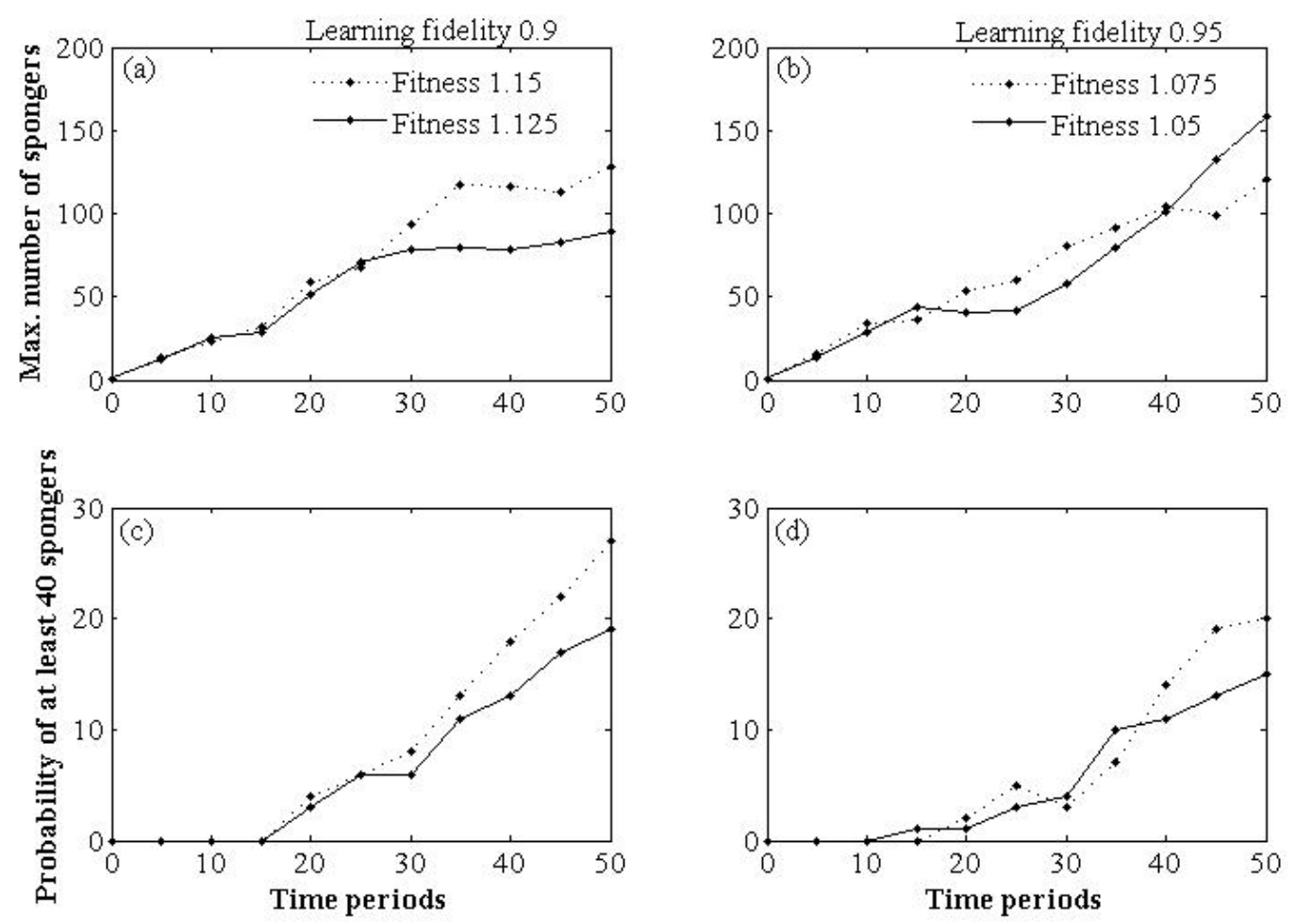

Figure A4: Actual maximum number of spongers and the probability (\%) to observe at least 40 spongers over time and over iterations. Simulations started with a single sponger ( $\mathrm{N}=100$ iterations in which at least one sponger was present in each time period). (a) and (b): maximum number of spongers observed. (c) and (d): corresponding probability to observe at least 40 spongers. Dashed lines indicate simulations with "favourable conditions" and solid lines indicate simulations with
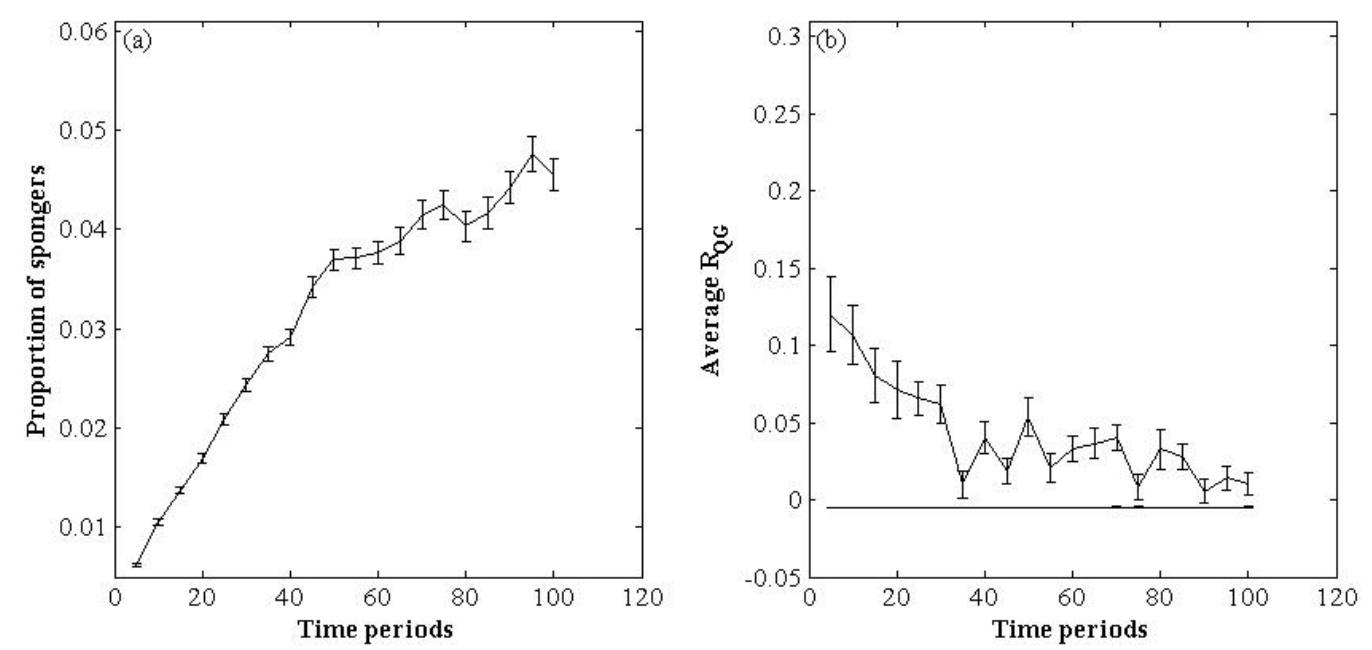

Figure A5: Proportion of female spongers within the population (a) and average pairwise relatedness among spongers over 100 time periods (b). Simulations started with a single sponger ( $\mathrm{N}=100$ iterations in which at least one sponger was present in each time period). Simulation parameter values: fitness benefits 1 , learning fidelity 1 . Error bars represent \pm 1 
903

904

905
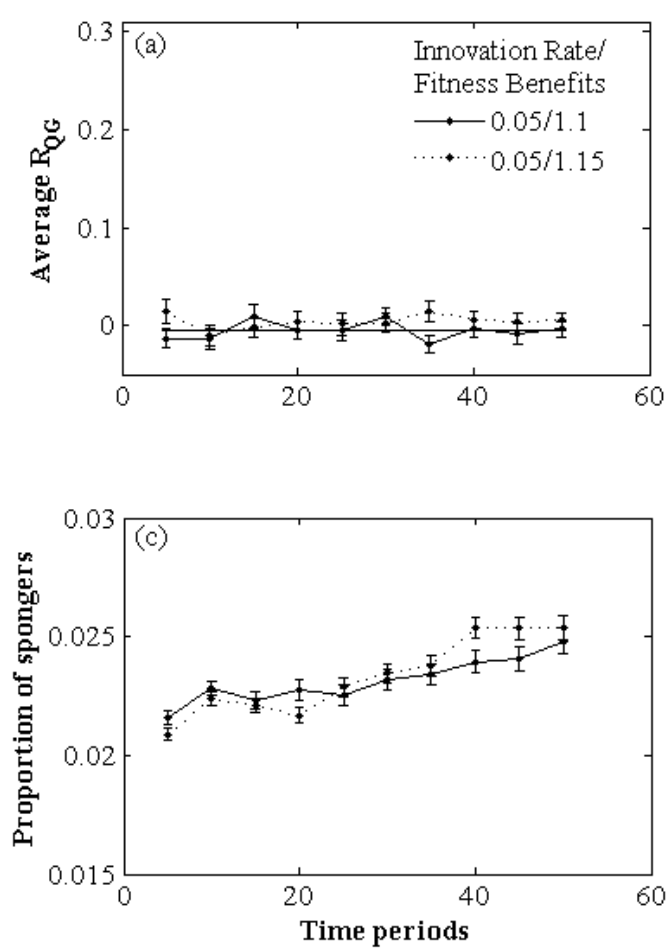
pairwise relatedness $\pm 1 \mathrm{SE}$.
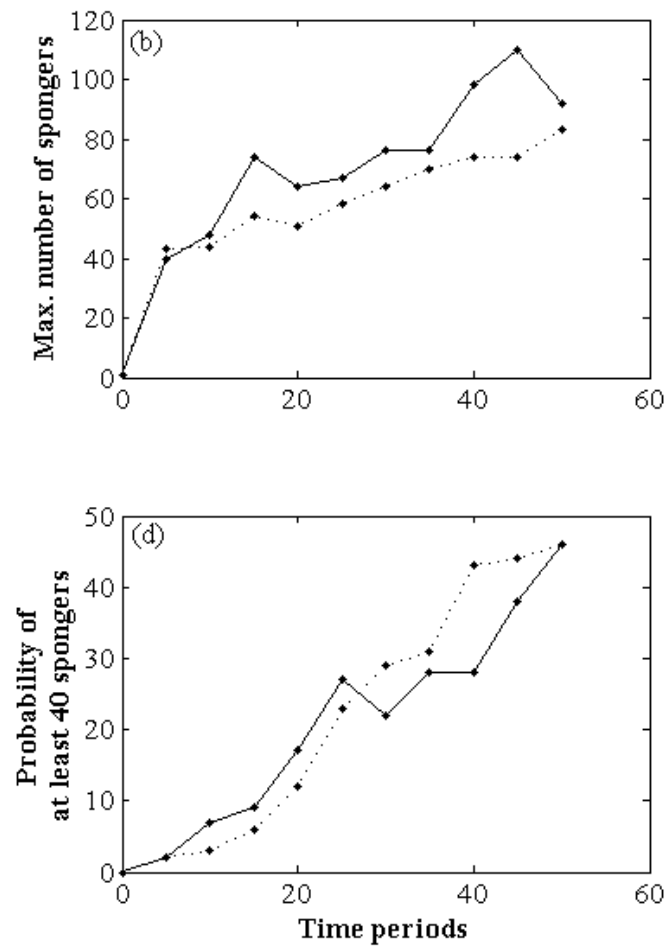

SE. The solid line at approximately $\mathrm{R}_{\mathrm{QG}}=0$ in (b) represents the population's average

Figure A6: Results of additional runs with sponging as an individually innovated trait and its influence on the average pairwise relatedness (Average $\mathrm{R}_{\mathrm{QG}}$ ) among spongers (a), the maximum number of spongers (b), the proportion of female spongers in the population (c), and the probability (\%) of observing at least 40 spongers in a population over time (d). 


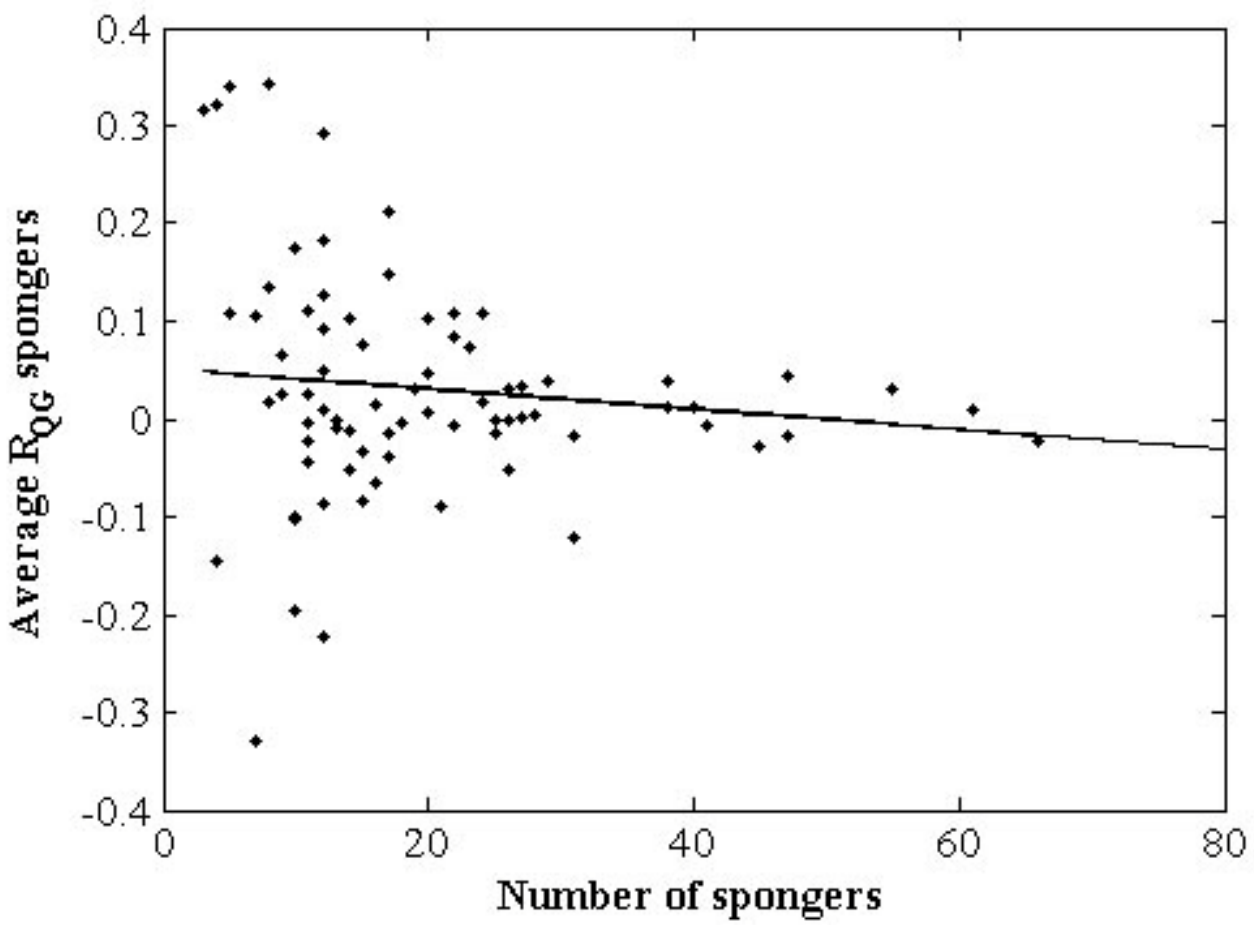

Figure A7: Correlation between the number of spongers and the average pairwise relatedness

914 among spongers. Each dot represents one iteration at 50 time periods from a simulation which 915 started with one sponger and did not include repeated innovations/horizontal transmission.

916 The line represents the non-significant $\left(\mathrm{R}^{2}=0.024, \mathrm{P}=0.177\right)$ trend line. Conditions of

917 simulations: Learning fidelity: 1, Fitness benefits: 1, Frequency of repeated

918 innovations/horizontal learning: 0 (corresponds to Run 1 in Appendix Table 5.A3). Under

919 these conditions and based on the trend line, the expected average pairwise relatedness of 40 (number observed in the western gulf) spongers is $\mathrm{R}_{\mathrm{QG}}=0.017$. 